\title{
DIALECTOMETRÍA Y LÉXICO EN LAS HABLAS DE TERUEL*
}

\author{
José Luis Aliaga JiméneZ \\ Universidad de Zaragoza \\ jlaliaga@unizar.es
}

\begin{abstract}
Resumen
The present paper approaches the dialectometric study of the linguistic varieties of Teruel based on the data provided by the Atlas Lingüistico Etnográfico de Aragón, Navarra y Rioja (1979-1983). This work presents a double interest. On the one hand, it attacks the analysis of a linguistic environment rarely analyzed so far as an autonomous form, and on the other, it fully makes use of the quantitative methods as focused on the dialectal analysis.
\end{abstract}

\section{Introducción}

La publicación del Atlas Lingüistico Etnográfico de Aragón, Navarra y Rioja (Alvar et alii, 1979-1983) abrió unas expectativas desconocidas hasta entonces para la filología aragonesa concretadas desde entonces en numerosas investigaciones que han tomado la información plasmada en los mapas de esta obra como objeto de estudio, de forma exclusiva o complementaria. Cuando se cumplieron diez años desde la aparición del primer volumen, la revisión bibliográfica de los frutos que había proporcionado su análisis arrojó un balance muy satisfactorio (Castañer y Enguita, 1989). Desde entonces ha transcurrido otra década y media, y los investigadores han continuado acudiendo a esa fuente de datos que no muestra por el momento síntomas de agotamiento'. Así pues, el $A L E A N R$ se sigue prestando a nuevas exploraciones desde diversos puntos de vista y la que aborda este trabajo resulta de interés, a nuestro juicio, desde dos perspectivas. En primer lugar, por aplicarse a las hablas turolenses ya que hasta la fecha la provincia de Huesca ha sido objeto de los tres estudios

\footnotetext{
* $\quad$ Este trabajo ha sido posible gracias a la ayuda recibida por el Instituto de Estudios Turolenses en la convocatoria de ayudas a la investigación de 1999.

1 No obstante, con el paso del tiempo, los materiales acopiados en el atlas tendrán que ser utilizados cada vez con mayor prevención si el investigador pretende extraer conclusiones fiables sobre el presente de la realidad lingüística aragonesa. No olvidemos que, de acuerdo con las ideas lingüísticas de la época, que primaban la búsqueda de pervivencias dialectales, se consideró informante idóneo para responder al cuestionario en cada localidad a quien, entre otros requisitos, tenía una edad de entre cincuenta y sesenta años. A ello debe añadirse que la mayoría de los mapas del $A L E A N R$ (1.394 sobre un total de 1.758) son de tipo léxico (el aspecto más cambiante de la lengua) y que las encuestas se llevaron a cabo entre 1963 y 1968 . Cabe referirse también a las consecuencias que se hayan podido derivar en la obtención de una cierta imagen de la realidad lingüística aragonesa (y de otros ámbitos) por la exclusión casi total de la mujer como informante en la encuesta dialectal. Puede consultarse, a este respecto, el número monográfico de la revista Orbis (1952) y, tambiẻn, García Mouton (1988 y 1999: 33-49) y Lozano (1995: 82-110).
} 
dialectométricos sobre las hablas aragonesas que conocemos (Guiter, 1983; Moreno, 1991 y García Mouton, 1991). En segundo lugar, porque el método dialectométrico (método cuantitativo aplicado al estudio de las diferencias y/o similitudes inter- o intralingüísticas) apenas ha sido explotado en la investigación sobre las modalidades lingüísticas españolas a diferencia de lo que ocurre para otras lenguas europeas. Por lo tanto, el trabajo que se desarrolla aquí desea contribuir, modestamente, a cubrir un hueco en la filología aragonesa desde el estudio básicamente cuantitativo de las modalidades lingüísticas de Teruel.

\section{Breve estado de la cuestión}

\subsection{Los estudios dialectológicos tradicionales sobre las hablas turolenses}

Como decimos, el objetivo que se ha trazado el presente estudio consiste en dibujar un nuevo panorama de la composición interna de las distintas modalidades lingüisticas que conviven en la provincia de Teruel mediante la aplicación de técnicas cuantitativas de análisis a los datos proporcionados por el $A L E A N R$. Las hablas de Teruel, como objeto de estudio, han sido incluidas generalmente en trabajos dialectológicos que engloban el conjunto del territorio aragonés o ámbitos más amplios y han sido escasas las monografías centradas en esta provincia. De hecho, sólo contamos con el trabajo de J. $\mathrm{M}^{\mathrm{a}}$. Enguita (1985) como obra de conjunto dedicada en exclusiva a las hablas vivas turolenses, un estado de la cuestión en el que se pone de relieve que la zona nororiental de la provincia turolense - de habla catalana- y los territorios limítrofes con ella han centrado el interés de las investigaciones sobre la región ${ }^{2}$. Con posterioridad al trabajo de Enguita tampoco contamos con un número excesivo de estudios de carácter cualitativo (esto es, centrados en la descripción de rasgos lingüísticos con independencia de su número de ocurrencias) que nos puedan servir de piedra de toque con la que contrastar nuestras conclusiones ${ }^{3}$. Cabe destacar, entre ellos, otro artículo del propio Enguita (1991a) para el conjunto del territorio aragonés estructurado de forma similar al dedicado a la provincia de Teruel ${ }^{4}$. Asimismo, nos servirá de instrumento contrastivo el apartado que M. ${ }^{\text {a }}$ R. Fort (1991) dedica a la penetración de rasgos catalanes en las zonas de habla castellana en un estudio sobre la Franja Oriental de Aragón. Y, finalmente, acudiremos a la comparación de nuestros mapas con las conclusiones a las que llega A. Llorente (1991) sobre la distribución de espacios lingüísticos en el interior de Aragón.

Advertiremos, no obstante, que los resultados lexicométricos de carácter estadístico, como los obtenidos en nuestro análisis, no son directamente cotejables con las conclusiones alcanzadas mediante la aplicación de métodos dialectológicos que podemos denominar

2 Por lo demás, el estudio de Enguita, a partir de una selección de mapas del $A L E A N R$, describe con precisión y por niveles de análisis (fonético, morfosintáctico y léxico), las huellas del antiguo romance aragonés en las hablas turolenses. Las conclusiones obtenidas quedan sintetizadas en un mapa-resumen (1985:219) sobre el que volveremos una vez expuestos nuestros resultados.

3 Nos referimos a monografias para cuya confección se haya manejado un amplio conjunto de datos entre los que se encuentren los de carácter léxico y que se hayan orientado al establecimiento de áreas lingüísticas. A este respecto pueden consultarse los estados de la cuestión sobre los diferentes ámbitos de la lingüística aragonesa contenidos en Enguita (1999).

4 Viene a representar una síntesis de sus estudios parciales circunscritos a las provincias aragonesas por separado. A la de Teruel, ya mencionado (Enguita, 1985), a la de Huesca (Enguita, 1988) y a la de Zaragoza (Enguita, 1991b). 
tradicionales, es decir, orientados al estudio de características dialectales contrastadas con las de una norma estándar de referencia. A diferencia del sistema de trabajo habitual en dialectología, los datos que conforman el corpus de trabajo en la medición lexicométrica no están sometidos a una criba previa para seleccionar los que puedan resultar rentables desde el punto de vista de una descripción contrastiva. Por lo tanto, las representaciones cartográficas de signo dialectométrico no dan cuenta de áreas o espacios dialectales del mismo modo que las tradicionales porque se derivan del cómputo de diferencias y/o semejanzas lingüísticas, tipológicamente dialectales o no. Sin embargo, la aplicación de este método también está encaminada a la detección de núcleos y zonas dialectales dado que la concentración de peculiaridades lingüísticas espaciales quedará reflejada con toda seguridad en el cálculo correspondiente. Nos hallamos, pues, ante un indudable ejemplo de aplicación de perspectivas lingüísticas complementarias sobre conjuntos de datos muy similares. En realidad, las mediciones estadísticas perderían a nuestro juicio buena parte de su interés si se prescindiera por completo del tipo concreto de fenómenos lingüísticos que constituye el transfondo de los índices y porcentajes matemáticos. En definitiva, intentaremos, con las oportunas precauciones, sacar provecho de la confrontación entre los resultados estadísticos y los cualitativos contenidos en los trabajos comentados más arriba.

\subsection{Los estudios dialectométricos sobre las modalidades lingüísticas aragonesas}

Tal como se ha indicado más arriba la mayoría de los estudios dialectométricos han sido desarrollados fuera de España. Pero la estadística ya se había utilizado de formas diversas a la medición de distancias lingüísticas antes de que se constituyera la disciplina denominada dialectometría (García Mouton, 1991: 312). Y en lo que se refiere a nuestro país, en los años cincuenta M. Alvar hizo uso de procedimientos cuantitativos en un estudio sobre las interferencias lingüísticas en la frontera catalano-aragonesa a partir del Atlas Lingüistico de Cataluña (Alvar, 1955). Después sólo encontramos tres estudios propiamente dialectométricos que tomen como objeto de estudio las hablas aragonesas. De ellos dos versan sobre la provincia de Huesca (Moreno, 1991; García Mouton, 1991) y otro, anterior, sobre la región cántabro-pirenaica donde queda incluida también la provincia más septentrional de Aragón (Guiter, 1983)

Por la proximidad de nuestro trabajo con ellos, nos interesan más concretamente los citados artículos de F. Moreno y de P. García Mouton, que incluyen una útil síntesis de las principales tendencias y principios dialectométricos ${ }^{6}$ y toman como corpus de trabajo respectivamente la morfología y el léxico del $A L E A N R$. Ambos siguen la misma metodología de cómputo consistente en medir diferencias lingüísticas comparando cada punto del atlas

5 Además contamos con otro (Séguy, 1971) donde se analizan materiales españoles (en concreto del Atlas Lingüístico de Cataluña y del Atlas Lingüistico Etnográfico de Andalucía).

6 Allí se nos informa de que la dialectometría es "una variante más en la síntesis de mapas" (Garcia Mouton, 1991: 312) que toma por objeto los datos geolingüísticos para elaborarlos estadísticamente. Esta metodología comenzó a desarrollarse en los años setenta y se afianzó una década después con un conjunto de trabajos elaborados en Francia y en Bélgica, sobre todo, y aplicados a distintos atlas lingüísticos del ámbito románico. Se puede decir que existen básicamente tres métodos, que no se excluyen mutuamente, de medir númericamente las distancias dialectales. Han sido desarrollados, respectivamente, por J. Séguy, E. Guiter y H. Goebl (García Mouton, 1991: 313-314; Moreno, 1991: 298-299). 
con todos los demás 7 . Efectuada la etapa de recuento se aplica una fórmula matemática para obtener un indice de diferenciación dialectométrica para cada localidad con un valor entre 0 y 1 . Cuanto más cercano a 1 se encuentre dicho índice mayor será la distancia lingüística de esa población respecto del resto de poblaciones estudiadas. Aparte del indice de diferenciación los datos permiten alcanzar otras conclusiones estadísticas, como la media de rasgos diferenciadores o la desviación típica, esclarecedoras de ciertos aspectos de la diferenciación lingüística de las localidades examinadas (Moreno, 1991: 300-302). De los valores obtenidos con el manejo de los ochenta mapas de morfología verbal utilizados por Moreno se desprende una configuración dialectal de las hablas oscenses que se ajusta con sorprendente precisión a las alcanzada por medios cualitativos (1991: 302-305). No ocurre lo mismo, sin embargo, con los resultados derivados del cómputo de diferencias léxicas que acomete García Mouton en cien mapas (1991: 321-324). En este caso, por ejemplo, la representación gráfica deja entrever en la Franja Oriental de Aragón una diferenciación interna horizontal -aparte de la orientada de norte a sur-que, en opinión de la citada investigadora, debe atribuirse en especial al modo de difusión del léxico, divergente en buena medida del de la fonética o del de la morfología (1991: 324-325).

\section{Metodología}

Señala H. Goebl (1987: 63) que la dialectometría es un procedimiento de clasificación numérica que comprende varias etapas en las que deben establecerse, sucesivamente, los datos que se van a clasificar; el modo de medición; el índice de similitud (o de diferenciación); los procedimientos estadísticos para explotar la tabla de similitud y el método de representar cartográficamente los resultados. Nuestro estudio se ajusta, en lo esencial, a la línea de trabajo y a los instrumentos de análisis empleados por Goebl. No obstante, dada la escasez de estudios dialectométricos publicados en España, nos inspiramos, en algunos aspectos, en las decisiones metodológicas de F. Moreno y P. García Mouton para facilitar la comparación de los resultados. A partir de ahí, en consonancia con el programa trazado por H. Goebl (1981; 1983; 1987), ampliamos sustancialmente la explotación estadística de los datos y la presentación gráfica de los resultados respecto de las llevadas a cabo para la provincia de Huesca en Moreno (1991) y García Mouton (1991).

\subsection{Selección del corpus y etapa de recuento}

En la selección del corpus de trabajo no sólo nos hemos ceñido a las consideraciones de García Mouton (1991: 315) -quien coincide con Guiter (1973) en la cifra de cien mapas como la cantidad mínima que asegura un rendimiento estadístico fiable- sino que nos ha parecido oportuno, además, analizar exactamente los mismos mapas léxicos del ALEANR que utiliza la citada autora porque resultan totalmente pertinentes los criterios de elección cia. 
aleatoria manejados (1991: 315-316) . Así pues, el corpus de datos originales que componen nuestro trabajo responde a las siguientes coordenadas:

1) Datos dialectales brutos: 100 mapas del $A L E A N R$.

2) Objetos (puntos del atlas): 36 puntos de la provincia de Teruel.

3) Criterio discriminatorio para la identificación de tipos léxicos diferenciados o taxats. diferencias léxicas.

4) Número total de tipos léxicos diferenciados (taxats): 685 .

5) Número de taxats por mapa: 6,85 .

Una vez transcrita la información de cada mapa en la matriz de datos (Goebl, 1981: 352) la etapa de recuento, como se ha señalado más arriba, se basa en la comparación de cada punto del atlas con todos los demás para, en la posterior etapa de cálculo, lograr índices estadísticos para cada localidad comparables con los de cualquiera de las otras. Así pues, en nuestro caso, Te 100 se compara con Te 101, Te 102, etc., hasta llegar a Te 601 . A continuación se coteja Te 101 con Te 102, Te 103, etc. El último escalón viene representado por la confrontación de Te 600 con Te 601. Por lo tanto, el modo de proceder en el cómputo es sencillo pero extremadamente laborioso porque se realiza de forma manual de principio a fin. El material necesario para proceder a la etapa de cálculo exige, en primer lugar, la transcripción de 3.600 formas léxicas (36 puntos de Teruel en el ALEANR de 100 mapas) que quedan registradas en la matriz de datos (véase un detalle en la Tabla 4). Posteriormente se procede a contabilizar las 630 distancias de diferenciación en 100 mapas y, en nuestro caso, a calcular otros 630 indices relativos de identidad, también sobre 100 mapas (vid. Tabla 5 y Tabla 5 , respectivamente) $)^{9}$.

No existe, que sepamos, un programa informático capaz de resolver los problemas metodológicos que surgen en el momento de decidir qué se contabiliza exactamente (con independencia de que se tomen en cuenta las coincidencias o las diferencias). Interviene necesariamente en esta fase el criterio subjetivo (que no arbitrario) del lingüista, que debe identificar los taxats, los tipos léxicos diferenciados (o morfosintácticos, en su caso) entre el polimorfismo que ofrecen habitualmente los mapas del atlas. Claro que un hipotético programa informático no contendría sino las instrucciones de las que le dotara un lingüista, aunque las ejecutara con mayor precisión. La bibliografía especializada apenas ofrece orientaciones prácticas en este punto crucial del análisis dialectométrico. Contamos con un escueto ejemplo proporcionado por H. Goebl (1987: 64, n. 5) mientras que García Mouton (1991), por

8 Los cien mapas que integran nuestro corpus llevan en el $A L E A N R$ la siguiente numeración: 16, 20, 24, 58, $81,92,128,149,156,161,166,174,222,236,239,252,254,270,286,323,335,336,361,418,434,439,468$, $483,495,515,523,541,546,560,567,577,586,592,602,614,621,627,645,657,661,689,702,723,726$, $739,741,765,797,814,854,861,870,872,936,937,942,944,946,960,968,981,982,992,1008,1035,1047$, $1096,1116,1118,1124,1129,1133,1179,1184,1211,1228,1230,1238,1240,1246,1260,1261,1268$, 1270, $1272,1286,1291,1310,1331,1342,1367,1385,1388,1393,1396$. Puede consultarse el nombre de cada mapa en García Mouton (1991: 317).

9 Desde un punto de vista técnico se calcula, en realidad, el doble de índices de similitud y de distancias de diferenciación (aqui supondrían un total de 1260) ya que se comparan las similitudes (o diferencias) tanto entre, por ejemplo, Te 100 y Te 101, como entre Te 101 y Te 100. Dado que la distancia de ambos recorridos es idéntica sólo es necesario anotar una de ellas. De ahí la forma asimétrica de la Tabla 5 y de la Tabla 7. 
su parte, facilita unas indicaciones útiles pero inevitablemente genéricas. A esta autora no le resulta totalmente convincente ni el criterio de agrupar todas las formas léxicas que comparten un mismo étimo ni el de establecer un corte allí donde el lingüista cree ver dificultada la comprensión de la palabra. Así, se decanta por otra solución: "hemos contado diferencias allí donde la fonética distorsionaba la identificación o un sufijo de diminutivo parecía lexicalizado" (1991: 318). Todavía podría apuntarse alguna otra pauta de actuación que no hemos visto señalada por ningún autor. Consistiría en articular un proceso de lematización que emulara el camino seguido para establecer la macroestructura de un diccionario a partir de un corpus textual sintetizando en una forma-tipo las unidades lingüísticas flexionadas y conjugadas del mismo paradigma. Los lematizadores automáticos empleados en lexicografía se desenvuelven ya con asombrosa precisión pero cabe preguntarse si admitirían, sin dejar de ser rentables, el grado de minuciosidad que exige el proceso dialectométrico en el que se manipulan, en buena medida, unidades léxicas alejadas del estándar. En cualquier caso, por muy acertada que pueda estimarse cualquiera de las medidas señaladas, hasta la fecha ninguna exime al dialectólogo de adoptar soluciones dictadas por su dominio de la materia en los casos problemáticos que, según nuestra experiencia, asoman con mayor frecuencia de lo señalado por García Mouton (1991: 318) ${ }^{10}$.

Tampoco existe unanimidad a la hora de tratar los casos de ausencia de respuesta en un punto del mapa, como Te 101 en el mapa 418 Santateresa o Te 200 en el 495 Puesto (Tabla 4). En estas situaciones el cálculo estadístico se verá afectado tanto si se opta por no contar una diferencia, posibilidad por la que se decanta Moreno (1991: 301), como si se adopta la solución contraria (García Mouton, 1991: 318-320) por la que nosotros nos hemos inclinado. Finalmente, no contamos diferencia en los casos en los que un punto de encuesta presenta varias respuestas y sólo una de ellas coincide con la del punto con el que se compara (García Mouton, 1991: 320). Así pues, no se anotaría una diferencia en la comparación de los puntos Te 100 y Te 200 con Te 101 en el mapa 361 Albaricoque (Tabla 4).

\subsection{Etapa de cálculo}

Las operaciones estadísticas a las que dan lugar el cómputo de diferencias y el de similitudes, respectivamente, están claramente diferenciadas y orientadas a la consecución de resultados complementarios. Por ello tratamos por separado cada una de las dos perspectivas. Nos limitamos en este tercer apartado a reseñar brevemente los aspectos técnicos reservando para el siguiente la interpretación de los datos más relevantes una vez comentado, asimismo, el método de representar cartográficamente los datos.

\subsubsection{Indice de diferenciación y desviación típica}

La Tabla 6 presenta para cada localidad las operaciones efectuadas a partir de la Matriz de diferenciación (Tabla 5). La primera columna indica el número de la localidad en el

10 Veamos un sencillo ejemplo. En el mapa 236 Acemite del ALEANR encontramos en la provincia de Teruel la serie de respuestas cabisuela, cabesuela, cabezuela. Parece claro que no debe contabilizarse ninguna diferencia entre ellas. Pero en el mismo mapa hallamos también la serie moyuelo, remoyuelo, remoelo, remoñuelo, remuñuelo, rebuñuelo, remogüelo. ¿Mostrarían unanimidad en este último caso todos los dialectólogos en que la fonética y la morfología distorsiona la identificación de la palabra? 
ALEANR; la segunda, la suma total de diferencias entre esa localidad y todas las demás; la tercera, la media de esas diferencias (el total de diferencias de cada punto dividido por 35 , es decir, por el número de localidades menos uno); la cuarta, la desviación típica y la quinta, el índice de diferenciación léxica. La desviación típica representa el alejamiento de una serie de números de su valor medio y se calcula promediando la suma de los cuadrados de todas las desviaciones individuales respecto de la media y tomando después la raíz cuadrada. La desviación típica nos informa, en un estudio dialectométrico, de si las diferencias de una localidad respecto de las demás es constante o si presenta variaciones acusadas según el punto con la que se compare en cada caso. El indice de diferenciación es igual a la suma total de diferencias de una localidad respecto de las demás dividida por el número de localidades estudiadas menos uno multiplicado por el número de mapas (Moreno, 1991: 301). Cuando se analizan cien mapas, como en este estudio, el índice de diferenciación se obtiene de forma más simple dividiendo por cien la media de diferencias de cada localidad (Tabla 6. columnas tercera y quinta). Como ya adelantamos más arriba, la modalidad lingüística de una localidad se halla más alejada de las demás cuanto más cercano a 1 se encuentre el valor del índice de diferenciación (véase la Figura l).

\subsubsection{Indice relativo de identidad}

Señala García Mouton que la Matriz de diferenciación puede leerse como una Matriz de similitud dándole la vuelta (1991: 318), lo cual resulta particularmente sencillo cuando se manejan cien mapas porque no es necesario operar para el cálculo del porcentaje. Por ejemplo, si como refleja la Tabla 5, las diferencias entre Te 202 y Te 203 suman 82 sobre $100(82 \%)$ la similitud entre esos dos puntos sería del $18 \%$. Sin embargo, esto es así siempre que no existan casillas vacías (puntos sin respuesta) en las localidades que se confrontan, al menos en la metodología estadística utilizada por H. Goebl (1981: 357-358; 1987: 68-69) al que seguimos en este aspecto. Así, para cada par de puntos comparados, el índice relativo de identidad (IRI) propuesto por Goebl se obtiene dividiendo el número de co-identidades por el de co-ocurrencias y multiplicando por cien el resultado. El número de co-ocurrencias equivale al número de mapas del corpus descontados los casos en que no exista respuesta en una localidad o en ninguna de las dos comparadas. Además, de producirse esta última circunstancia no se computa ni una semejanza ni una diferencia de modo que, en la práctica, se utiliza un mapa menos. Siguiendo con la muestra anterior, el IRI entre Te 202 y Te 203 es el $18,681 \%$ (véase Tabla 7), ligeramente superior, por lo tanto, al $18 \%$ que resultaría de una estimación especular de la Matriz de diferenciación. Este porcentaje responde al hecho de que entre una localidad y otra suman 91 co-ocurrencias (ocho casillas vacías y una novena, la correspondiente al mapa 1228 Maestro", que no tiene respuesta en ninguno de los dos puntos). Por lo tanto, el número de diferencias es de 82 y el número de semejanzas es de 17 (99 en total). El $I R I(18,681 \%)$ resulta, así, de dividir 17 por 91 y multiplicar por 100 la cifra resultante ${ }^{\mathrm{II}}$.

11 El $I R I$ no es la única posibilidad para medir la similitud entre dos puntos del atlas. $H$. Goebl se ha servido en otros estudios del denominado indice ponderado de identidad (IPI). Mientras que en el cálculo del IRI se les adjudica el valor 1 a todas las co-identidades entre dos puntos del atlas, con el IPI se persigue otorgar un mayor peso a las co-identidades cuanto menor sea la frecuencia absoluta en el resto de los puntos del atlas de los taxats que generan esas co-identidades. Ello responde al principio estadístico de que la coincidencia de aspectos extraños 


\subsubsection{Otras operaciones estadísticas significativas}

Conviene precisar, antes de continuar, que el conjunto de valores de similitud respecto de un punto de referencia constituye una distribución de similitud. Así, existen tantas distribuciones de similitud como puntos del atlas estudiados y cada distribución está compuesta por tantos valores como localidades menos uno (precisamente, el punto de referencia). En nuestro estudio contamos con 36 distribuciones de similitud de 35 valores cada una (véase Tabla 7). Cada distribución de similitud puede dar lugar a la elaboración de, al menos, un mapa sinóptico, pero a partir de ella son posibles tantas presentaciones cartográficas como algoritmos de visualización sean utilizados (véase el apartado 3.3). En la práctica, se suelen reproducir gráficamente en mapas las distribuciones de similitud cuyo punto de referencia pertenece a alguna localidad en la que se presentan indicios estadísticos que pueden resultar reveladores para la comprensión de la configuración lingüística de la zona estudiada. En nuestro trabajo nos hemos decantado por las distribuciones correspondientes a los puntos de referencia Te 104 (Barrachina), Te 202 (Calaceite) y Te 204 (La Codoñera), localidades en las que concurrían características cuantitativas de acusada personalidad, como se explica más abajo. Cada distribución de similitud ha sido proyectada en tres mapas aplicando tres algoritmos distintos de visualización. Todo ello ha dado lugar, por lo tanto, a la confección de nueve presentaciones gráficas diferenciadas (véanse las Figuras 5 a 13).

Al margen de lo anterior, entre los elementos significativos, estadísticamente hablando, con que contamos en cada distribución de similitud se encuentra el valor máximo, esto es, el porcentaje de coincidencias lingüísticas más elevado de una localidad con otra (véase la Tabla 8). El valor máximo de una distribución suele aparecer, por lo general, en la comparación con una localidad próxima al punto de referencia. E1 tratamiento cartográfico de los valores máximos de cada distribución (véase la Figura 2) permite identificar la localización y extensión de los diversos núcleos dialectales del territorio estudiado (Goebl, 1981: 383). No menos interés ofrece el análisis de la media aritmética de cada distribución (véase la Tabla 8) cuya sinopsis gráfica (véase la Figura 3) nos informa sobre las zonas cuya modalidad lingüística ocupa una posición central en la red de puntos examinada y desempeña una función de mediación que facilita la intercomprensión comunicativa en la red de puntos examinada (Goebl 1981: 388). Finalmente, es necesario referirse al cálculo y valor explicativo del índice de simetría. Aunque contamos con procedimientos sumamente complejos para determinar un coeficiente de simetría riguroso es posible obtener un índice de simetría aceptable desde el punto de vista estadístico recurriendo al sencillo cálculo del cociente entre el valor máximo y la media aritmética de una distribución de similitud (Goebl, 1981: 394 y 406), opción de la que nos hemos servido en este estudio (véanse la Tabla 8 y la Figura 4). La medición de la simetría pone de relieve la conexión de un punto en el seno de una red determinada, conexión que será mayor cuanto más cercano a cero se encuentre el resultado de la operación descrita.

o singulares cuenta con menos probabilidades de suceder que la de aspectos usuales o comunes y, por ello, al primer tipo de coexistencia se le debe otorgar un mayor peso cuantitativo (Goebl, 1987). Así, si nos ciñéramos a la matriz de datos presentada en la Tabla 4, la co-identidad en el mapa 336 Desgajar entre los puntos Te 102 y Te 103 alcanzaría un mayor valor numérico, en un indice ponderado, que la co-identidad de esas mismas localidades en el mapa 515 Serrano, porque la respuesta serrano (515) se repite en todos los demás puntos de encuesta mientras que rasgar (336) sólo aparece Te 102 y Te 103. 


\subsection{La representación gráfica}

Es preciso, en este punto, referirse a dos aspectos de distinto orden. Por un lado, el puramente gráfico, la disposición que adopta el fondo del mapa sobre el que se vierten los resultados de las operaciones matemáticas. De entre las opciones manejadas habitualmente por las diferentes escuelas dialectométricas, la triangulación y el trazado poligonal de Thiessen, hemos elegido la confección geométrica en polígonos que transforma la representación discreta, por puntos, de un atlas lingüístico en otra de carácter continuo ${ }^{12}$. Conviene puntualizar, no obstante, que la triangulación y el trazado poligonal no son disposiciones gráficas completamente equivalentes o con las mismas capacidades explicativas (Goebl, 1983).

Por otro lado, hay que referirse al procedimiento empleado para organizar de forma discreta en el mapa poligonal una variación numérica continua, en nuestro caso la variación numérica de cada distribución de similitud. Para cada una de las distribuciones de similitud estudiadas aquí -la de Te 104, Te 202 y Te 204- hemos aplicado los tres algoritmos de visualización (o intervalización) descritos por Goebl, a los que este autor identifica, respectivamente, con las siglas MINMWMAX, MEDMW y MED (1981: 361-368; 1987: 79-90) ${ }^{13}$. Como en el caso de los tipos de articulación gráfica del fondo del mapa, cada algoritmo sirve a una finalidad taxométrica particular. Las diferencias básicas consisten en el hecho de que el algoritmo MINMWMAX está concebido para generar una visualización poco accidentada de la distribución dialectométrica de un territorio. El MEDMW y el MED, por su parte, tienden a poner de relieve las microzonas dialectales del territorio estudiado pero el primero de forma progresiva y menos abrupta que el segundo. Los tres algoritmos comparten, eso sí, la propiedad de convertir en clases discretas la variación numérica continua de toda distribución de similitud. No está prefijado el número de clases más adecuado para segmentar una variación numérica cualquiera, aunque Goebl, al que seguimos, ha utilizado por lo general una parcelación en seis intervalos asignando a cada uno de ellos un tipo diferenciado de trama tintada que nosotros hemos reemplazado por una escala de grises (véanse las Figuras 2 a 13 ).

El algoritmo MINMWMAX se obtiene del siguiente modo: 1) se calcula la media aritmética de la distribución de similitud; 2) se divide por tres la diferencia entre la media aritmética y el valor mínimo de la distribución para obtener la cifra que corresponde a la extensión de los intervalos situados por debajo de la media. Con la dimensión del intervalo resultante se establecen los límites de los tres intervalos por debajo de la media aritmética y, en consecuencia, los valores de la distribución (puntos del atlas) que aglutina cada intervalo; 3) se realiza la misma operación para la diferencia entre la media aritmética y el máximo de la distribución de similitud. En la Tabla 1 presentamos, como ejemplo, el resultado de la aplicación del algoritmo MINMWMAX a la distribución que tiene como punto de referencia a Te 202 (véase también la Tabla 7 y la Figura 8): 


\begin{tabular}{|c|c|c|c|c|}
\hline Intervalo & de & hasta & $\begin{array}{c}\text { Tamaño del } \\
\text { intervalo }\end{array}$ & $\begin{array}{c}\text { Número de puntos del atlas por } \\
\text { intervalo }\end{array}$ \\
\hline 1 & 52,747 & 41,862 & 10,885 & 2 \\
\hline 2 & 41,862 & 30,977 & 10,885 & 1 \\
\hline 3 & 30,977 & $20,092 *$ & 10,885 & 6 \\
\hline 4 & 20,092 & 17,226 & 2,866 & 8 \\
\hline 5 & 17,226 & 14,36 & 2,866 & 16 \\
\hline 6 & 14,36 & 11,494 & 2,866 & 2 \\
\hline \multicolumn{2}{r|}{} & $\begin{array}{c}* \text { Media } \\
\text { aritmética }\end{array}$ & & Total: 35 \\
\cline { 2 - 4 } & & &
\end{tabular}

Tabla 1

Por su parte, el algoritmo MEDMW resulta de las siguientes operaciones: 1) se ordenan de menor a mayor los 35 valores, en nuestro caso, de la distribución de frecuencia elegida; 2) se busca el valor más próximo a la media aritmética; 3) el conjunto de valores que se encuentran entre el mínimo y el valor más próximo, y entre éste y el valor máximo forman, respectivamente, un grupo cada uno; 4) cada uno de estos dos grupos se divide en tres clases iguales, en la medida de lo posible, tomando como criterio el número de puntos del atlas por clasificar. La tabla resultante para el punto Te 202 (Tabla 2) presenta las características que se señalan a continuación (véanse también la Tabla 7 y la Figura 9):

\begin{tabular}{|c|c|c|c|c|}
\hline Intervalo & de & hasta & $\begin{array}{c}\text { Tamaño del } \\
\text { intervalo }\end{array}$ & $\begin{array}{l}\text { Número de puntos del } \\
\text { atlas por intervalo }\end{array}$ \\
\hline 1 & 52,747 & 25,274 & 27,473 & 3 \\
\hline 2 & 25,274 & 21,59 & 3,684 & 3 \\
\hline 3 & 21,59 & $19,354^{*}$ & 2,236 & 3 \\
\hline 4 & 19,354 & 17,021 & 2,333 & 8 \\
\hline 5 & 17,021 & 16,091 & 0,93 & 9 \\
\hline 6 & 16,091 & 11,494 & 4,597 & 9 \\
\hline & & $\begin{array}{l}\text { *Valor próximo a la } \\
\text { media aritmética }\end{array}$ & & Total: 35 \\
\hline
\end{tabular}

Tabla 2

Finalmente, el algoritmo MED requiere los cálculos que ahora se detallan: 1) se ordenan de menor a mayor los 35 valores, en nuestro caso, de la distribución de frecuencia elegida; 2) los 35 valores se reparten en seis grupos iguales, en la medida de lo posible, ya que pueden ser necesarios algunos ajustes, como para Te 202, para que valorès iguales no queden encuadrados en intervalos diferentes. El manejo del algoritmo MED para clasificar la distribución de similitud del punto Te 202 da lugar a la Tabla 3 (véanse también la Tabla 7 y la Figura 10): 


\begin{tabular}{|c|c|c|c|c|}
\hline Intervalo & de & hasta & Tamaño del intervalo & Número de puntos del atlas por intervalo \\
\hline 1 & 52,747 & 23,333 & 29,414 & 5 \\
\hline 2 & 23,333 & 18,888 & 4,445 & 6 \\
\hline 3 & 18,888 & 17,021 & 1,867 & 6 \\
\hline 4 & 17,021 & 16,129 & 0,892 & 5 \\
\hline 5 & 16,129 & 15,294 & 0,835 & 6 \\
\hline 6 & 15,294 & 11,494 & 3,8 & 7 \\
\hline
\end{tabular}

Tabla 3

\section{La interpretación de los resultados}

\subsection{La distancia lingüística entre las hablas turolenses}

Para cartografiar el indice de diferenciación léxica hemos distinguido siete intervalos, como puede apreciarse en la Figura 1, con el objeto de lograr una percepción de las distancias lingüísticas algo más matizada de la que hubiera surgido de discriminar sólo dos grupos, en lugar de cuatro, entre los valores más bajos. No procedía, sin embargo, efectuar la misma operación para los puntos que ofrecían los valores más altos de diferenciación ya que no había localidades con índices entre, por ejemplo, 0,79 y $0,75 \mathrm{y}$, de hecho, podían distinguirse tres intervalos para sólo cuatro localidades, extremo que da fe por sí solo de las peculiaridades locales del habla de las poblaciones de la Franja Oriental de Aragón. Asi, mientras Calaceite (Te 202) alcanza el mayor índice de diferenciación de toda la provincia $(0,81)$, Valderrobres (Te 205) y Peñarroya (Te 207) presentan índices elevados, homogéneos entre sí ( 0.727 y 0,733 , respectivamente) pero sensiblemente inferiores al de Calaceite (véase la Tabla 6) ${ }^{14}$. Por su parte, La Codoñera (Te 204), con un índice muy alejado del de las otras poblaciones de habla catalana $(0,629)$, comienza a mostrar un perfil estadístico altamente peculiar que se verá confirmado por todos los demás indicadores manejados en este estudio.

Si atendemos a la comparación entre las cuatro poblaciones de habla catalana deteniéndonos en los datos de la Tabla 5, vemos que Calaceite se distingue en 51 casos tanto de Valderrobres como de Peñarroya las cuales, de nuevo, se comportan de un modo muy similar y sólo se separan entre sí por 43 diferencias. Pero nuestro recuento arroja un total de 69,58 y 60 diferencias entre La Codoñera y Calaceite, Valderrobres y Peñarroya, respectivamente. Esto quiere decir que La Codoñera se distancia de Calaceite más que cualquier localidad de habla castellana de otra con la misma modalidad, aunque en algunas ocasiones se superan entre éstas las 60 diferencias (61 diferencias entre Bordón - Te 401- y Santa Eulalia - Te 304- o entre Puertomingalvo -Te 600 - y Villar del Saz -Te 303-). Se puede argüir, con razón, que ninguna población castellanohablante se acerca tanto como La Codoñera al habla de Calaceite, ya que respecto de esta última las diferencias oscilan entre las 76 de Iglesuela

14 Recordaremos aquí la coincidencia con M. Alvar (1955) quien, con distinto método, cifró en un $79,5 \%$ el componente catalán del habla de Calaceite a partir del Atles Lingüistic de Catalunya (Barcelona, Institut d'Estudis Catalans, 1923-1936). Véanse también los comentarios de Moreno sobre este aspecto en la provincia de Huesca (1991: 303). 
del Cid (Te 405) y las 89 de Villar del Saz (Te 303). Pero adoptando otro punto de vista se puede argumentar, con igual razón, que la modalidad lingüística de La Codoñera, estadísticamente y de acuerdo con los datos manejados del $A L E A N R$, tiene menos relación con Calaceite que con cualquier otra localidad de habla castellana si exceptuamos Masegoso (Te 500) con la que mantiene 72 diferencias.

A propósito de los valores indicados en la Tabla 6 es obligado, antes de cualquier otra consideración, subrayar la considerable magnitud de los porcentajes medios (columna tercera) y, por lo tanto, de los índices de diferenciación (columna quinta) de muchas localidades castellanohablantes de Teruel. De hecho, si comparamos nuestros resultados con los obtenidos por García Mouton en su análisis de Huesca (1991: 321) -recuérdese que se han examinado los mismos mapas del $A L E A N R$ en ambos trabajos-- llama poderosamente la atención que la media del porcentaje de diferencias léxicas y del índice de diferenciación en el conjunto de Teruel alcanzan cifras más elevadas $(52,43 \%$ y 0,524$)$ que las medias obtenidas para la provincia norteña de Aragón $(50,26 \%$ y 0,502$)$. A primera vista, no deja de constituir un dato cuando menos llamativo si consideramos que la considerable fragmentación lingüística de las modalidades altoaragonesas es uno de los rasgos distintivos de las hablas norteñas frente a las meridionales de Zaragoza y Teruel. Podría pensarse, en primer lugar, en una diferencia metodológica consistente en una discriminación de tipos léxicos (taxats) por nuestra parte más fraccionada que la realizada por García Mouton ${ }^{15}$. Pero un intento de valorar este aspecto presentaría no pocos inconvenientes. Por un lado, el catálogo de tipos léxicos es una información que, como señalamos más arriba, no se facilita en los estudios consultados. Y en lo que se refiere concretamente al $A L E A N R$, la diversidad de respuestas en el mismo mapa no tiene por qué coincidir -y, de hecho, rara vez coincide- entre las localidades de una y otra provincia ${ }^{16}$.

No obstante, aun en el caso de que la agrupación de ciertas variantes léxicas lograra disminuir en algunas centésimas la media de diferenciación de las hablas turolenses, el porcentaje citado continuaría siendo notablemente elevado y merecedor de otras reflexiones. En este sentido, no puede obviarse el hecho de que, cualitativamente, el ALEANR certifica la existencia de un extraordinario grado de diversidad léxica en las hablas turolenses, diversidad que quizá pueda explicarse por la pervivencia de vocabulario tipológicamente dialectal o por influjo catalán en ciertas zonas, pero que responde asimismo a una notoria variación interna del español regional. De los 100 mapas estudiados, 73 acumulan cinco o más tipos léxicos y ninguno de los restantes resultó ser mononímico. La media de taxats por mapa, como se apuntó más arriba, alcanzó la cifra de 6,85. Reparemos ahora en otro aspecto. Según las estimaciones de F. Moreno (1991: 304) una media de diferenciación por encima del $70 \%$ apuntaría a la presencia de un sistema lingüístico diferente. Si el porcentaje no al-

\footnotetext{
15 Si un investigador aisla, por ejemplo, tres tipos léxicos donde otro distingue cinco, el número final de diferencias léxicas resultará algo mayor en el segundo caso. Si esta circunstancia se repite siempre en el mismo sentido la imagen final de las diferentes distancias lingüísticas mostrará quizá variaciones de cierta importancia sin que, necesariamente, una versión pueda calificarse como más adecuada o fiel que la otra si están justificados los criterios utilizados por ambos dialectólogos.

16 Por ello, aunque hemos adoptado los criterios diferenciadores expuestos por la citada autora (1991: 315 320) nos hemos enfrentado a materiales de trabajo parcialmente divergentes. Sólo una investigación paralela sobre idénticos materiales - los mismos mapas de una sola zona- podría poner de manifiesto la entidad de las hipotéticas discrepancias de método a las que nos referimos.
} 
canza el 50\% podríamos considerar que se trata de un habla de tipo castellano y los valores intermedios darían cuenta de un espacio claramente dialectal. En una línea similar, aunque de forma menos rotunda, se pronuncia García Mouton (1991: 324). De acuerdo con estas apreciaciones -y al margen del comentario que requieren de nuevo los datos de La Codoñera (Te 204)- debemos llamar la atención sobre las diecisiete localidades castellanohablantes de Teruel cuya media de diferenciación rebasa el $50 \%$ de diferencias léxicas ${ }^{17}$. Todas ellas, a excepción de Torrijo (Te 301) y Villar del Saz (Te 303) se sitúan significativamente en la mitad oriental de la provincia, precisamente en la zona en la que los estudios cualitativos -que sopesan, no olvidemos, la fonética, la morfosintaxis y el léxico- han detectado mayor índice de rasgos dialectales aragoneses (Enguita, 1985) o de influjo catalán (Fort, 1991).

Cabe inducir de ello que, en términos globlales, la medición cuantitativa viene a complementar la aproximación tradicional para confirmarla: los valores situados entre el 50 y el 55 por ciento de diferenciaciación darían cuenta, así, de unas hablas dialectalmente peculiares por uno u otro condicionante. Sin embargo, no resultaría acertada una simplificación excesiva porque algunas situaciones no encajan en una explicación general como la anterior. Por ejemplo, ni Muniesa (Te 102) ni Estercuel (Te 206) -con índices de 0,474 y 0,477 , respectivamente- se distancian llamativamente del resto pese a ser dos de los puntos más conservadores de caracteres aragoneses junto con Hijar, Alloza y Mas de las Matas, según la aproximación de Enguita (1985: 204). En sentido contrario, Alcañiz (Te 201), cuya modalidad cataloga este mismo investigador entre las más castellanizadas de Teruel y pertenece, como las anteriores, al rincón noreste de la provincia, arroja un índice de 0,559 , la distancia lingǘstica más elevada de toda la zona castellanohablante de Teruel junto con la de Bordón (Te 401), asimismo con 0,559 (véase la nota 18). En cuanto a la zona de influjo catalán, cabe decir que las hablas de Fortanete (Te 404) y Alcalá (Te 406) poseen un índice de diferenciación poco relevante $(0,465$ y 0,478$)$ y, sin embargo, ambas localidades pertenecen al grupo de las que exteriorizan la mayor impronta del catalán de toda la provincia según Fort (1991: 197-198), aspecto este último que también se pone de relieve en nuestro corpus, en especial, en el caso de Fortanete (véase el apartado 4.3.).

Contamos, por otro lado, con el caso contario. El elevado índice $(0,558)$ de Masegoso (Te 500) no responde, a juzgar por nuestros datos, a la destacada presencia en su habla de rasgos catalanes detectada por Fort (1991: 197-198) sino a la de usos léxicos distintivos en el marco del español regional -extremo ratificado por su relativamente baja desviación típi$c a-y$, del mismo modo, al hecho de que en once mapas el informante no respondió. Estas casillas vacías representan una diferencia fija en la comparación con el resto de los puntos salvo que la respuesta falte en los dos, como ya se señaló más arriba. Algo muy similar sucede con Puebla de Valverde (Te 501), cuyo índice de 0,516 es atribuible en parte a los ocho

17 Son las siguientes (véase la Tabla 3): Te 200 Hijar, Te 201 Alcañiz, Te 203 Alloza, Te 301 Torrijo, Te 303 Villar del Saz, Te 307 Cedrillas, Te 400 Mas de las Matas, Te 401 Bordón, Te 403 Tronchón, Te 405 Iglesuela del Cid, Te 500 Masegoso, Te 501 Puebla de Valverde, Te 502 Riodeva, Te 503 Manzanera, Te 504 Arcos de las Salinas, Te 600 Puertomingalvo y Te 601 Olba. Ciertamente, algunas superan por escaso margen esa cantidad (Alloza, Torrijo, Tronchón, Iglesuela del Cid y Riodeva) pero otras alcanzan el 55\% o se acercan a esa cifra (Híjar, Alcañíz, Bordón, Masegoso y Olba). Interesa, por ello, subrayar que sólo seis de esas diecisiete localidades sobrepasan el porcentaje y el índice medio de diferenciación (52,43\% y 0,524): Te 200 Híjar, Te 201 Alcañiz, Te 401 Bordón, Te 500 Masegoso, Te 504 Arcos de las Salinas y Te 601 Olba. A éstas se suman las localidades catalanohablantes, por encima asimismo de los valores medios: Te 202 Calaceite, Te 204 La Codoñera, Te 205 Valderrobres y Te 207 Peñarroya. 
mapas sin respuesta y, en menor medida, con Tronchón (Te 403) aunque en once ocasiones el encuestador no consiguiera la información requerida. Son todas ellas, localidades poco afines al catalán según el corpus manejado aquí, lo que no se corresponde con las conclusiones de una aproximación cualitativa (Fort, 1991: 197-198). Sin embargo, a pesar de las once casillas vacías de Olba (Te 601) y de las siete de Bordón (Te 401) ambas localidades se siguen mostrando próximas al catalán (véase el apartado 4.3.) ${ }^{18}$. En cualquier caso, no deseamos magnificar las discrepancias, que asoman sobre un dibujo de fondo claramente común a las dos perspectivas de análisis, según venimos diciendo, y no constituyen necesariamente contradicciones. Más bien debe pensarse, para estos casos, en un estrato de discrepancias (y afinidades) entre las distintas hablas que capta una aproximación cuantitativa pero no una cualitativa y viceversa. También cabe anticipar una consecuencia crítica relativa a la metodología adoptada: quizá deba compensarse el corpus de trabajo, perteneciente en exclusiva al nivel léxico, con el tratamiento conjunto de mapas morfológicos y fonéticos, posibilidad por la que se decantó H. Guiter en algún trabajo (1973) a diferencia de la práctica observada por J. Séguy (1971).

Sin embargo, en el extremo opuesto de los indicadores de la Tabla 6 se perfila un cuadro altamente esclarecedor y mucho más acorde con las descripciones tradicionales. Las nueve localidades con menor media e índice de diferenciación se encuentran en torno al eje que podemos trazar entre Barrachina (Te 104) y Aliaga (Te 402), los dos puntos menos diferenciados de Teruel $o$, en otras palabras, con un habla menos específica (índices de 0,429 y 0,426 ). Predominan en este grupo las poblaciones del cuadrante noroeste de la provincia (Te 101 Ferreruela, Te 102 Muniesa, Te 300 Montalbán, Te 302 Visiedo) con una ligera penetración hacia el sur (Te 305 Alfambra) y hacia el este (Te 206 Estercuel y Te 404 Fortanete). Ocupan el ámbito en el que convergen todas las tendencias lingüísticas de la provincia sin que ninguna ostente una posición de dominio. Por un lado, cinco de esas nueve poblaciones (Estercuel, Visiedo, Aliaga, Alfambra y Barrachina) forman parte de una zona intermedia de penetración occidental de rasgos catalantes (Fort, 1991: 197-198). Por otro, se sitúan en el límite entre la zona más conservadora de rasgos aragoneses y la más castellanizada (Enguita, 1985: 204-205; 1991a: 125-151). Esta equidistancia explica la escasa magnitud de sus valores de diferenciación y también las elevadas desviaciones típicas, que nos advierten de la pobre peculiaridad de las hablas de esta franja. Este último dato no puede ser más revelador. A excepción de la de Fortanete -a cuya particularidad ya nos hemos referido más arriba- todas las hablas de esta área, que podemos denominar zona de convergencia, alcanzan unas desviaciones típicas por encima de la media, situada en 10,28, empezando por Barrachina (Te 104) con la más alta de toda la provincia $(13,94)^{19}$.

18 Los ocho mapas sin respuesta explican, asimismo, el índice $(0,522)$ de Villar del Saz (Te 303) localidad del extremo occidental de Teruel. Por su parte, Torrijo (Te 301) también en la parte occidental, sólo excede en dos milésimas del índice del $0,5(0,502)$ por lo que, dentro de su peculiaridad, se mueve en los límites de las localidades de su entorno. Finalmente, el índice $(0,559)$ de Alcañiz (Te 201) se ve afectado al alza por las siete casillas vacías del corpus, pero no podemos perder de vista que, como Masegoso, Alcañiz posee una desviación típica $(9,05)$ muy inferior a la media $(10,28)$ indicativa de un habla marcadamente singular.

19 El trazado de áreas lingüísticas propuesto para Aragón por R. Castañer (1990: 371) viene a confirmar plenamente nuestra interpretación. El ámbito que hemos denominado zona de convergencia se corresponde casi con total precisión con un área en torno a Te 206 Estercuel, Te 300 Montalbán y Te 402 Aliaga, donde se encuentran las isoglosas que delimitan los cuatro espacios dialectales del español que Castañer descubre en la provincia meridional de Aragón. 
Casi todas las demás desviaciones típicas que superan la media conciernen a un grupo homogéneo de localidades emplazadas en el cuadrante centro-occidental, en contacto estrecho con las hablas castellanas de Guadalajara (Te 103 Bello, Te 301 Torrijo, Te 303 Villar del Saz, Te 304 Santa Eulalia, Te 306 Noguera y Te 308 Teruel). Son hablas muy cercanas entre sí (menos de cuarenta diferencias de media) y muy alejadas del resto, en especial, de la mitad oriental. En sentido contrario, entre los puntos con una menor desviación típica ocupan un lugar destacado los de habla catalana, al igual que en la provincia de Huesca (García Mouton, 1991: 321). Son, lógicamente, hablas que, al margen del influjo que ejercen de modo más o menos acusado en el entorno castellanohablante, se oponen de forma muy parecida a casi todas las demás, incluyendo en ocasiones a las propias de la Franja Oriental. Al margen de esto, el cuadrante suroriental reúne a un grupo nutrido de hablas singularizadas por su reducida desviación típica: Cedrillas (Te 307), Iglesuela del Cid (Te 405), Manzanera (Te 503), Puertomingalvo (Te 600) y Olba (Te 601). Pero son particularmente llamativas las desviaciones típicas más reducidas del conjunto. Bordón (Te 401), con 7,52, posee la segunda más baja de Teruel, menor incluso que la resultante en las poblaciones de la Franja si exceptuamos la atingente a La Codoñera (Te 204), con tan sólo un 3,45, que merece un comentario aparte a la vista de su personalidad estadística (véase el apartado 4.3.). Bordón, por su parte, comparte con Alcañiz el mayor índice de diferenciación del español regional de Teruel $(0,559)$ e igual cantidad de mapas -siete-- sin respuesta. Pero, además, el informante de Bordón facilitó un número apreciable de formas léxicas muy peculiares que aclaran la reducida desviación típica.

\subsection{EI valor máximo, la media aritmética y el índice de simetría}

Decíamos más arriba que el cartografiado de los valores máximos de una distribución de similitud permitía detectar la ubicación de focos dialectales relevantes. Así lo confirman las características de la Figura 2, que permiten reconocer con bastante nitidez las siguientes zonas:

1) Área de la Franja Oriental, de habla catalana, a cuya delimitación poco se puede añadir salvo quizá el hecho de que el elevado nivel de similitud (IRI superior al 61\%) entre Valderrobres (Te 205) y Peñarroya (Te 207) sitúa a estos puntos en el tercer intervalo de visualización y no en el primero, al que se adscriben Calaceite y La Codoñera.

2) Área conservadora de rasgos autóctonos aragoneses (Enguita, 1985: 204-205; Castañer, 1990: 371), menos destacada en el mapa que en los datos (véase la Tabla 7 ) y aglutinada en torno a Estercuel (Te 206), localidad frente a la cual alcanzan el valor máximo de similitud Híjar (Te 200), Alloza (203) y Bordón (Te 401). A su vez, el IRI más elevado de Estercuel se emplaza en Aliaga (Te 402), al igual que el de Mas de las Matas (Te 400).

3) Área de la zona noroeste de Teruel, perfectamente caracterizada en los estudios tradicionales por su acentuada castellanización, su vinculación lingüística con el extremo suroeste de Zaragoza y por quedar al margen, casi por completo, de la influencia del catalán. Estas propiedades, conjunta o individualmente, se ponen de relieve en las investigaciones de Castañer (1990: 371), Fort (1991: 197-198), Enguita (1991a: 150; 1991b: 220) y Llorente (1991: 181). El epicentro de éste ámbito parece ser Barrachina (Te 104) que congrega el IRI máximo en las distribuciones de similitud de Nogueras (Te 100), Ferreruela (Te 101), 
Muniesa (Te 102), Bello (Te 103), Montalbán (Te 300) y Visiedo (Te 302). A su vez el valor máximo de Barrachina se origina en la comparación con Ferreruela.

4) Área del sector sureste de Teruel, de influencia valenciana (Castañer, 1990: 317; Fort, 1991: 197-198; Llorente, 1991: 180-181). De acuerdo con nuestros datos sus centros serían Alcalá (Te 406) y Puebla de Valverde (Te 501). En la primera se agrupan las máximas de Puertomingalvo (Te 600), Olba (Te 601) y Cedrillas (Te 307) y en la segunda las de Manzanera (Te 503) y Arcos de las Salinas (Te 504). La máxima de Alcalá queda emplazada, a su vez, en Puertomingalvo y la de Puebla de Valverde en Olba.

La validez del procedimiento taxométrico seguido se pone de manifiesto, de igual modo, en las Figuras 3 y 4 . En la primera se representa la distribución de la media aritmética del indice relativo de identidad de cada punto del ALEANR en Teruel. La disposición centrífuga resultante (de una magnitud mayor en el centro a una menor en la periferia) nos está indicando la posición relativa de las hablas turolenses de una perspectiva comunicativa mediadora entre las distintas corrientes dialectales. No por casualidad cobra de nuevo protagonismo la región distinguida más arriba como zona de convergencia, ahora con un peso mayor de las hablas-puente hacia el sur y el sureste concretadas en Alfambra (Te 305) y Fortanete (Te 404). Por su parte, la Figura 4, sintesis gráfica de la distribución del indice de simetría, adopta una disposición en forma de de aspa. Quedan así trazados los ejes a través de los cuales discurren las zonas de contacto entre los espacios dialectales de la provincia, surcada, por un lado, por el eje noreste-suroeste, verdadero nexo de enlace entre el ámbito más vinculado lingüísticamente al oriente de la península y el más castellanizado. Los núcleos de mayor conectividad aparecen en los extremos del eje, en La Codoñera (Te 204) y Riodeva (502). Por otro, esta línea se ve atravesada en dirección noroeste-sureste por el eje Barrachina-Montalbán-Aliaga-Fortanete (que reaparece para proporcionar nueva información) donde se concentran las hablas que sirven de engarce entre el área más conservadora de rasgos que entroncan con el antiguo dialecto, en el noreste, y la que parece más distanciada del romance autóctono, en el suroeste.

\subsection{Las distribuciones de similitud relativas a los puntos Te 104, Te 202 y Te 204}

Hemos escogido para su cartografiado, de entre todas las posibles, las distribuciones de similitud relativas a tres puntos cuyos valores despuntan por alguna propiedad estadística. Ya nos hemos referido en varias ocasiones a los indicadores de La Codoñera (Te 204). Parecía de interés conocer las vinculaciones lingüísticas de una modalidad con un rendimiento estadístico tan distanciado del de todas las demás. En el caso de Barrachina (Te 104) y Calaceite (Te 202) porque se trataba de los puntos que arrojan los valores extremos de la media aritmética del $I R I(60,715$ y 20,092 , respectivamente). Esto es, por representar respecto del resto de Teruel el habla más similar (Barrachina) y la menos parecida (Calaceite). De acuerdo con el corpus manejado, podemos interpretar el dato de Calaceite como el indicador de que nos hallamos ante la modalidad más catalana, en el sentido de la más cercana al catalán estándar y menos impregnada de castellanismos (Quintana, 1976-80: 190-191). En consecuencia, su distribución de similitud nos orienta sobre qué variedades dialectales presentan más cercanía con el catalán. Sin embargo, no podemos deducir, a partir de nuestro corpus, que Barrachina posea la modalidad más castellanizada de la provincia sino sólo la menos peculiar o, dicho de otro modo, la más parecida a todas las demás. Sabemos, no obstante, 
que a esta localidad alcanza muy débilmente el influjo tanto catalán como aragonés y, al mismo tiempo, se encuentra en la órbita de las hablas castellanas limítrofes con Aragón ${ }^{20}$. Creemos, pues, que todo ello autoriza, con las debidas precauciones, a tomar Barrachina como término de referencia con el que valorar la mayor o menor castellanización de las hablas turolenses.

$\mathrm{Y}$ lo cierto es que, aunque el juego de grises se ha utilizado con criterio inverso, los mapas correspondientes a la distribución de similitud de Barrachina (Figuras 5, 6 y 7 ) sugieren una imagen casi invertida de los correspondientes a Calaceite (Figuras 8, 9 y 10). En términos generales, las concomitancias con Calaceite disminuyen conforme se avanza hacia el oeste mientras que con Barrachina se degradan en sentido opuesto. Cabe matizar, claro está, que las coincidencias lingüísticas con Barrachina quedan de manifiesto, sobre todo, en el cuadrante noroccidental y en la llamada zona de convergencia -y son algo inferiores con el suroeste dé Teruel- y que, sin embargo, las discrepancias más acusadas respecto de Calaceite quedan patentes a lo largo de toda la frontera con Cuenca, Guadalajara y el suroeste de Zaragoza. Nótense, por otro lado, cómo los algoritmos de visualización acentúan las diferencias, más difuminadas con la aplicación del MINMWMAX, más abruptas con el MED. En la distribución de Barrachina, por ejemplo, el polígono de Cedrillas (Te 307) asciende de intervalo con cada algoritmo, alejándose del punto de referencia, hasta encuadrarse en el primero, junto con los puntos de habla catalana en el mapa de la Figura 7. En la distribución de Calaceite, las hablas de Fortanete (Te 404) e Iglesuela del Cid (Te 405) se muestran más catalanizadas con el algoritmo MEDMW y, en un grado mayor, con el MED. Puede apreciarse, también, que el algoritmo MED ayuda a perfilar la personalidad de la frontera con el valenciano en el sureste de Teruel (Figuras 7 y 10).

Queda, por último, referirse a la distribución de similitud de La Codoñera (Te 204). Se ha comentado ya la singularidad de los valores estadísticos de este punto de la Franja, tanto en el indice de diferenciación, como en el indice de simetría o en la media aritmética del IRI. Con el algoritmo MINMWMAX, tampoco se comporta igual que las otras poblaciones de habla catalana turolenses del $A L E A N R$, como se aprecia en los mapas correspondientes a Barrachina y Calaceite (Figuras 5 y 8 ). Así, se puede afirmar que, estadísticamente y en el marco de las hablas turolenses, la modalidad lingüística de La Codoñera está menos diferenciada que la de Calaceite, Valderrobres y Peñarroya, ocupa una posición menos marginal que la de éstas y su nivel de conectividad con las hablas de su entorno es el máximo de la provincia mientras que el de Calaceite, Valderrobres y Peñarroya es mínimo. Se acerca más al habla castellana de Barrachina que las otras variedades catalanas y se parece menos a la modalidad catalana de Calaceite que las hablas de Valderrobres y Peñarroya. El cartografiado de la distribución de similitud de La Codoñera (Figuras 11, 12 y 13) viene a ratificar los comentarios precedentes al mostrar una compleja red de afinidades y discordancias que no nos atrevemos a calificar de irregular. En una primera aproximación habría que subrayar, lógicamente, que su modalidad se encuentra más estrechamente vinculada a las del sector

20 Para calcular numéricamente la distancia del habla de cada localidad respecto del estándar -en este caso, respecto del español estándar- sin recurrir a las descripciones cualitativas podría hacerse uso de la solución manejada habitualmente por $\mathrm{H}$. Goebl. Consiste en la introducción, como una población más, de un punto artificial representante del estándar. Sus datos estarían integrados por los nombres de cada mapa, pertenecientes, por lo general, a la variedad de referencia. 
oriental de Teruel. Pero no debe perderse de vista el número de poblaciones occidentales que ocupan los intervalos tercero y cuarto, así como los puntos orientales emplazados en los tres últimos intervalos, empezando por Calaceite. El arco que describen los puntos taxométricamente más próximos a La Codoñera, dejando aislados algunos puntos limítrofes con el valenciano, hace emerger la conexión de esta población con la segunda línea de influjo catalán en las hablas castellanas de Teruel. No por casualidad, con los algoritmos MEDMW y MED particularmente (Figuras 12 y 13), la distribución de similitud de La Codoñera presenta evidentes puntos de contacto con la del indice de simetría (Figura 4), donde se asocia con localidades de carácter lingüístico fronterizo antes que con otras de contornos más delimitados.

En definitiva, si tuviéramos que juzgar en exclusiva por las implicaciones cuantitativas, calificaríamos el habla de La Codoñera como típicamente fronteriza, subdialectal y de pronunciada singularidad al mismo tiempo. Salvando las distancias, desempeñaría en Teruel el papel que ocupan en Huesca la modalidad de Benasque o, en cierta medida, la de Gistaín. Pero las investigaciones dialectológicas cualitativas no apuntan a una caracterización de esa naturaleza al describir el habla de La Codoñera. Es conocida la controversia sobre la adscripción lingüística del benasqués al aragonés o al catalán, es decir, su carácter híbrido, al menos desde el punto de vista taxonómico. La filiación aragonesa del chistavino no se pone en tela de juicio aunque algunos rasgos, como el perfecto perifrástico, lo vinculen en alguna medida al romance peninsular más oriental. Sin embargo, a propósito del habla de La Codoñera, A. Quintana concluye que "no té justificació parlar ací de català de transició a l'aragonès o al castellà o bé al revés" sino de una "variant del català occidental" (197680: 6). Admite, claro está, sus propiedades distintivas de carácter comarcal y local. En sus aspectos más significativos, éstas se concretan, en el plano fónico, en un sistema vocálico de cinco vocales (en lugar de siete), en un sistema consonántico en el que tiene cabida el fonema $/ \theta /$ interdental fricativo sordo, en la presencia de diptongación $[j a ́$ ] en lugar de la [é] abierta del catalán occidental y, en el nivel léxico, en la considerable concurrencia de localismos, arcaísmos y castellanismos. La Codoñera está ubicada en el valle del río Guadalope, compartido con poblaciones castellanohablantes entre las que se encuentra el importante centro comarcal de Alcañiz. Sin embargo, Calaceite, Valderrobres y Peñarroya se encuentran enclavadas en el valle del río Matarraña, más oriental, en contacto directo con las hablas catalanas de Tarragona, territorio con el que Calaceite y otros pueblos próximos mantuvieron vínculos históricos en el pasado al estar adscritos al obispado de Tortosa y no al de Zaragoza.

\section{Conclusiones}

No sabríamos decir si la mirada propuesta aquí sobre las hablas de Teruel encaja en la categoría de nueva perspectiva sobre datos dialectales actuales o en la de revisión de viejos materiales (García Mouton, 1991: 326). El coste temporal en la confección de los atlas lingüísticos y el tipo de informante, de edad avanzada, privilegiado por la geografia lingüística, obligan a que, transcurridos unos años, la interpretación de las informaciones tan laboriosamente recopiladas y transcritas deba incluir alguna referencia a la vigencia sincrónica de las informaciones. Todo ello no resta validez, claro está, a los resultados que se puedan alcanzar. Sólo relativiza su extrapolación cronológica. 
En el marco del método dialectométrico las hablas de Teruel han sido examinadas a lo largo de estas páginas en sus diferencias y semejanzas. No hemos agotado, por supuesto, todos los cálculos estadísticos que permitían los materiales recopilados, que son susceptibles todavía de aprovechamientos ulteriores. Pero, aun ciñéndonos a las operaciones que hemos considerado más relevantes, hemos logrado que las modalidades lingüísticas turolenses dispongan de la descripción dialectométrica más detallada que, hasta donde conocemos, se ha ensayado para las hablas peninsulares. Con ella se han visto ratificados muchos de los aspectos anticipados por la dialectología tradicional. Pero también se han sacado a la luz ciertas discrepancias que, en parte, podrían ser imputables a la selección exclusiva de un corpus de mapas léxicos, pero que se derivan también, no se olvide, de que dialectología y dialectometría operan de distinta manera y, en definitiva, cada una de ellas crea un objeto propio con su particular punto de vista.

\section{Referencias bibliográficas}

Alvar, M. (1955): "Catalán y aragonés en las regiones fronterizas". En Actas del VII Congreso Internacional de Lingiuistica Románica. Barcelona, págs. 737-778.

Alvar, M. et alii (1979-1983): Atlas Lingiiístico Etnográfico de Aragón, Navarra y Rioja. 12 vols., Zaragoza, IFC-CSIC.

Castañer, R. (1990): Estudio del léxico de la casa en Aragón, Navarra y Rioja. Zaragoza, DGA.

Castañer, R. y J. M." Enguita (1989): "Una década de estudios sobre el ALEANR", AFA, 42-43, págs. 241-257.

Enguita, J. M." (1985): "Rasgos dialectales aragoneses en las hablas de Teruel", Teruel, 74, págs. 179-219.

Enguita, J. M." (1988): "Panorama lingüístico del Alto Aragón”, AFA, 41, págs. 175-191.

Enguita, J. M." (1991a): "Modalidades lingüísticas del interior de Aragón". En Actas del I Congreso de Lingüistas Aragoneses. Zaragoza, DGA, págs. 103-151.

Enguita, J. M.“ (1991b): "Las hablas de Zaragoza”. En J. M. a Enguita (ed.), págs. 201-239.

Enguita, J. M." (ed.): I Curso de Geografia Lingüística de Aragón. Zaragoza, IFC.

Enguita, J. M." (ed.) (1999): Jornadas de Filología Aragonesa en el L Aniversario del AFA. 2 vols., Zaragoza, IFC.

Fort, M. ${ }^{a}$ R. (1991): "Hablas orientales". En J. M." Enguita (ed.), págs. 185-199.

García Mouton, P. (1988): "Sobre la mujer en la encuesta dialectal", RDTP, 43, págs. 291-299.

García Mouton, P. (1991): "Dialectometría y léxico en Huesca”. En J. M. "Enguita (ed.), págs. 311326.

García Mouton, P. (1999): Cómo hablan las mujeres. Madrid, Arco/Libros.

Goebl, H. (1976): "La dialectométrie appliquée a l'ALF (Normandie)". En A. Varvaro (ed.): Atti del XIV Congresso Internazionale di Lingüistica e Filologia Romanza. II, Amsterdam, págs. 165195.

Goebl, H. (1981): "Éléments d'analyse dialectométrique (avec application à l'AIS)", $R L R, 45$, págs. $349-420$.

Goebl, H. (1983): "Parquet polygonal et treillis triangulaires: les deux versants de la dialectométrie interponctuelle", $R L R, 47$, págs. 353-412.

Goebl, H. (1987): "Points chauds de l'analyse dialectométrique: pondération et visualisation", RLR, 51, págs. 63-118.

Guiter, H. (1973): "Atlas et frontières linguistiques". En G. Straka y P. Gardette (eds.): Les dialectes de France à la lumière des atlas régionaux (Colloque de Strasbourg, 1971). Paris, págs. 61-109. 
Guiter, H. (1983): "Aproximació lingüística a la cadena cantabro-pirenenca". En Miscel-lània Aramon i Serra. III, Barcelona, págs. 230-254.

Guiter, H. (1985): "Les méthodes quantitatives en géolinguistique sont-elles equivalentes?". En Actes del XVI Congreso Internacional de Lingüistica y Filologia Románicas. II, Barcelona, Ed. Moll, págs. 355-367.

Guiter, H. (1987): "Étalonnage d'une méthode géolinguistique", $R L R, 51$, págs. 55-62.

Llorente, A. (1991): "Fronteras lingǘsticas internas en territorio aragonés". En J. M." Enguita (ed.), págs. 165-184.

Lozano, I. (1995): Lenguaje femenino, lenguaje masculino. ¿Condiciona muestro sexo la forma de hablar? Madrid, Minerva Ediciones.

Moreno, F. (1991): "Morfología en el ALEANR: aproximación dialectométrica". En J. M." Enguita (ed.), págs. 289-309.

Quintana, A. (1976-80): "El parlar de La Codonyera. Resultats d'unes enquestes", Estudis Romànics, XVII, págs. 1-253.

Saramago, J. (1986): "Differentiation lexicale (un essai dialectométrique appliqué aux materiaux portuguais de l'ALE)", Géolinguistique, II, págs. 1-31.

Séguy, J. (1971): "La relation entre la distance spatiale et la distance lexicale", $R L R$, 35, págs. 335357.

Séguy, J. (1973): "La dialectométrie dans l'ALG", RLR, 37, págs. 1-24.

Verlinde, S. (1988): "La dialectométrie et la détection des zones dialectales: l'architecture dialectale de l'Est de la Belgique romane", RLR, 51, págs. 151-172.

Viereck, W. (1988): "The Computerisation and Quantification of Linguistic Data: Dialectometrical Methods". En A. R. Thomas (ed.): Methods in Dialectology. Clevedon, Phi., Multilingual Matters, págs. 406-427. 


\section{APÉNDICE}

\begin{tabular}{|l|l|l|l|l|l|l|l|l|l|}
\hline $\begin{array}{l}\text { MAPA } \\
\text { LOCALIDAD }\end{array}$ & $\mathbf{3 3 6}$ & $\mathbf{3 6 1}$ & $\mathbf{4 1 8}$ & $\mathbf{4 3 4}$ & $\mathbf{4 3 9}$ & $\mathbf{4 6 8}$ & $\mathbf{4 8 3}$ & $\mathbf{4 9 5}$ & $\mathbf{5 1 5}$ \\
\hline $\begin{array}{l}100 \\
\text { NOGUERAS }\end{array}$ & esgarrar & albericoque & margarita & tocinico & sanguijuela & cuchareta & bacalau & esperadera & serrano \\
\hline $\begin{array}{l}101 \\
\text { FERRERUELA }\end{array}$ & esgarrar & $\begin{array}{l}\text { alberge/ } \\
\text { abaricoque }\end{array}$ & XXX & ciempiés & sangrijuela & cuchareta & $\begin{array}{l}\text { abadejo/ } \\
\text { bacalao }\end{array}$ & espera & serrano \\
\hline $\begin{array}{l}102 \\
\text { MUNIESA }\end{array}$ & rasgar & albericoque & grillo & $\begin{array}{l}\text { gusano de } \\
\text { ciengarras }\end{array}$ & sandrijuela & $\begin{array}{l}\text { ranueco/ } \\
\text { cuchareta }\end{array}$ & $\begin{array}{l}\text { abadejo/ } \\
\text { bacalao }\end{array}$ & esperadero & serrano \\
\hline $\begin{array}{l}103 \\
\text { BELLO }\end{array}$ & rasgar & albericoque & rezadora & milpiés & sanguijuela & renacuajo & abadejo & esperadera & serrano \\
\hline $\begin{array}{l}104 \\
\text { BARRACHINA }\end{array}$ & esgarrar & albericoque & señorita & ciempiés & sangrijuela & cuchareta & $\begin{array}{l}\text { abadejo/ } \\
\text { bacalao }\end{array}$ & esperadero & serrano \\
\hline 200 KITAR & esgarrar & alberge & maría & ciengarras & sangrijuela & gucharón & $\begin{array}{l}\text { abadejo/ } \\
\text { bacalau }\end{array}$ & XXX & $\begin{array}{l}\text { montañés/ } \\
\text { serrano }\end{array}$ \\
\hline
\end{tabular}

Tabla 4. Matriz de datos (detalle)

\begin{tabular}{|c|c|c|c|c|c|c|c|c|c|c|c|c|c|c|c|c|c|c|c|c|c|c|c|c|c|c|c|c|c|c|c|c|c|c|c|c|}
\hline & 100 & $10 \mathrm{I}$ & 102 & 103 & 104 & 200 & 201 & 202 & 203 & 204 & 205 & 206 & 207 & 300 & 301 & 382 & \begin{tabular}{|l|}
303 \\
\end{tabular} & 304 & 305 & 306 & 307 & 308 & 400 & 401 & 402 & 403 & 404 & 405 & 406 & 500 & 501 & 502 & 503 & 504 & 600 & 601 \\
\hline 100 & & & & & & & & & & & & & & & & & & & & & & & & & & & & & & & & & & & & \\
\hline 101 & 31 & & & & & & & & & & & & & & & & & & & & & & & & & & & & & & & & & & & \\
\hline \begin{tabular}{|l|}
102 \\
\end{tabular} & 33 & 32 & & & & & & & & & & & & & & & & & & & & & & & & & & & & & & & & & & \\
\hline 103 & 43 & 32 & 33 & & & & & & & & & & & & & & & & & & & & & & & & & & & & & & & & & \\
\hline 104 & 28 & 24 & 27 & 27 & & & & & & & & & & & & & & & & & & & & & & & & & & & & & & & & \\
\hline \begin{tabular}{|l|l|}
200 \\
\end{tabular} & 47 & 44 & 48 & 44 & 41 & & & & & & & & & & & & & & & & & & & & & & & & & & & & & & & \\
\hline \begin{tabular}{|l|}
201 \\
\end{tabular} & 50 & 50 & 52 & 53 & 48 & 45 & & & & & & & & & & & & & & & & & & & & & & & & & & & & & & \\
\hline 202 & 86 & 86 & 85 & 87 & 86 & 85 & 85 & & & & & & & & & & & & & & & & & & & & & & & & & & & & & \\
\hline 203 & 46 & 42 & 41 & 42 & 40 & 39 & 49 & 82 & & & & & & & & & & & & & & & & & & & & & & & & & & & & \\
\hline 204 & 68 & 62 & 64 & 65 & 63 & 65 & 57 & 69 & 58 & & & & & & & & & & & & & & & & & & & & & & & & & & & \\
\hline 201 & 79 & 76 & 77 & 78 & 76 & 77 & 78 & 51 & 74 & 58 & & & & & & & & & & & & & & & & & & & & & & & & & & \\
\hline 206 & 44 & 40 & 39 & 42 & 32 & 41 & 47 & 81 & 38 & 59 & 72 & & & & & & & & & & & & & & & & & & & & & & & & & \\
\hline 207 & $\overline{81}$ & 79 & 78 & 78 & 76 & 78 & 78 & 51 & 71 & 60 & 43 & 73 & & & & & & & & & & & & & & & & & & & & & & & & \\
\hline 300 & 34 & 39 & 40 & 44 & 32 & 42 & 46 & 82 & 47 & $6 !$ & 75 & 32 & 72 & & & & & & & & & & & & & & & & & & & & & & & \\
\hline \begin{tabular}{|l|}
301 \\
\end{tabular} & 50 & 40 & 45 & 37 & 38 & 55 & 55 & 84 & 49 & 63 & 74 & 47 & 77 & 45 & & & & & & & & & & & & & & & & & & & & & & \\
\hline 302 & 41 & 30 & 44 & 39 & 29 & 49 & 53 & 83 & 45 & 66 & \begin{tabular}{|l|}
78 \\
\end{tabular} & 42 & 74 & 37 & 39 & & & & & & & & & & & & & & & & & & & & & \\
\hline \begin{tabular}{|l|}
303 \\
\end{tabular} & 45 & 40 & 46 & 43 & 37 & 54 & 50 & 89 & 50 & 63 & 81 & 53 & 83 & 46 & 43 & 35 & & & & & & & & & & & & & & & & & & & & \\
\hline \begin{tabular}{|l|}
304 \\
\end{tabular} & 44 & 37 & 41 & 43 & 37 & 55 & \begin{tabular}{|l|}
57 \\
\end{tabular} & 85 & 50 & 63 & 76 & 49 & 76 & 43 & 31 & 40 & 41 & & & & & & & & & & & & & & & & & & & \\
\hline 305 & 35 & 35 & 37 & $4 !$ & 30 & 53 & 49 & 82 & 42 & 64 & 77 & 41 & 74 & 39 & 38 & 32 & 42 & 33 & & & & & & & & & & & & & & & & & & \\
\hline 306 & 45 & \begin{tabular}{|l|}
40 \\
\end{tabular} & 38 & 41 & 36 & 52 & 54 & 86 & 49 & 64 & 76 & 47 & 79 & 40 & 38 & 41 & 38 & 41 & 41 & & & & & & & & & & & & & & & & & \\
\hline 307 & 54 & 52 & 54 & 59 & 49 & 62 & 59 & 81 & 49 & 64 & 68 & 52 & 73 & 53 & 46 & 45 & 56 & 51 & 41 & 44 & & & & & & & & & & & & & & & & \\
\hline \begin{tabular}{|l|}
308 \\
\end{tabular} & 43 & 38 & 38 & 42 & 36 & 55 & 56 & 82 & \begin{tabular}{|l|}
50 \\
\end{tabular} & 66 & 77 & 47 & 80 & 46 & 43 & 44 & 43 & 35 & 34 & 32 & 45 & & & & & & & & & & & & & & & \\
\hline 400 & 50 & 45 & 46 & 51 & 44 & 56 & 45 & 83 & 46 & 59 & 76 & 45 & 78 & 50 & 50 & 48 & 50 & 46 & 44 & 50 & 51 & 45 & & & & & & & & & & & & & & \\
\hline 401 & 58 & 52 & 52 & 57 & 48 & 53 & 59 & 80 & 54 & 69 & 73 & 42 & 69 & 51 & 61 & \begin{tabular}{|l|}
53 \\
\end{tabular} & 59 & 61 & 52 & 59 & 55 & 60 & 50 & & & & & & & & & & & & & \\
\hline 402 & 38 & \begin{tabular}{|l|}
32 \\
\end{tabular} & 33 & 36 & 28 & 41 & 47 & 84 & 37 & 57 & 70 & 28 & 74 & 34 & 41 & 37 & 45 & 41 & 34 & 35 & 44 & 36 & 38 & 49 & & & & & & & & & & & & \\
\hline \begin{tabular}{|l|}
403 \\
\end{tabular} & 49 & \begin{tabular}{|l|}
47 \\
\end{tabular} & 52 & 54 & 45 & 56 & 55 & 83 & 50 & 64 & 76 & 50 & 74 & 49 & 55 & 41 & 49 & 51 & 41 & 45 & 50 & 47 & 46 & 50 & 38 & & & & & & & & & & & \\
\hline \begin{tabular}{|l|}
404 \\
\end{tabular} & \begin{tabular}{|l|}
44 \\
\end{tabular} & 43 & 45 & 47 & 38 & 53 & 52 & 79 & 49 & 60 & 65 & 43 & 69 & 43 & 50 & 45 & 49 & 45 & 38 & 42 & 47 & 40 & 44 & 50 & 29 & 33 & & & & & & & & & & \\
\hline \begin{tabular}{|l|}
405 \\
\end{tabular} & 52 & 53 & 50 & 55 & 43 & 56 & 59 & 76 & 51 & 64 & 69 & 46 & 71 & 49 & 51 & 43 & 56 & 54 & 47 & 51 & 43 & 50 & 51 & 45 & 41 & 45 & 34 & & & & & & & & & \\
\hline \begin{tabular}{|l|}
406 \\
\end{tabular} & 48 & 48 & 44 & 47 & 40 & 53 & 56 & 84 & \begin{tabular}{|l|}
44 \\
\end{tabular} & 61 & 74 & 48 & 79 & 46 & $4 !$ & 40 & 54 & 47 & 32 & 43 & 39 & 42 & 46 & 55 & 33 & 43 & 39 & 43 & & & & & & & & \\
\hline 500 & 55 & 46 & 52 & 53 & 45 & 58 & 61 & 86 & 57 & 72 & 79 & 57 & 81 & 48 & 53 & 46 & 53 & 51 & 50 & 47 & 53 & 53 & 56 & 56 & 52 & 54 & 52 & 53 & 53 & & & & & & & \\
\hline 501 & 46 & 47 & 45 & 52 & 44 & 54 & 60 & 85 & 55 & 63 & 75 & 46 & 74 & 45 & \begin{tabular}{|l|}
56 \\
\end{tabular} & 47 & 54 & 53 & 47 & 49 & 47 & 50 & 55 & 53 & 43 & 50 & 44 & 49 & 48 & 53 & & & & & & \\
\hline \begin{tabular}{|l|}
502 \\
\end{tabular} & 52 & 42 & 45 & 45 & 43 & 52 & 49 & 84 & 48 & 62 & 78 & 43 & 75 & 44 & 48 & 44 & 46 & 41 & 38 & 42 & 54 & 42 & 52 & 57 & 40 & 50 & 45 & 51 & 49 & 49 & 49 & & & & & \\
\hline 503 & \begin{tabular}{|l|}
53 \\
\end{tabular} & 53 & 48 & 52 & 47 & 60 & 61 & 82 & 55 & 62 & 73 & 50 & 72 & 49 & 54 & 45 & 56 & 50 & 43 & 52 & 45 & 52 & 55 & 54 & 46 & 51 & 45 & 46 & 44 & 51 & 37 & 46 & & & & \\
\hline \begin{tabular}{|l|}
504 \\
\end{tabular} & 50 & 46 & 50 & 55 & 48 & 58 & 57 & 85 & 54 & 62 & 74 & 54 & 76 & 47 & 51 & 52 & 60 & 45 & 44 & 49 & $\overline{45}$ & 47 & 54 & 58 & 46 & 47 & 42 & 52 & 42 & 52 & 41 & 52 & 44 & & & \\
\hline 600 & \begin{tabular}{|l|}
53 \\
\end{tabular} & 53 & 53 & 53 & 48 & 58 & 61 & 78 & 51 & 60 & 69 & 48 & 69 & 53 & 53 & 49 & 61 & 57 & 50 & 47 & 46 & 54 & 53 & 51 & 36 & 41 & 37 & 42 & 32 & 61 & 51 & 51 & 48 & $5 \overline{3}$ & & \\
\hline 601 & 53 & 52 & 53 & 57 & 50 & 59 & 64 & 78 & 54 & 67 & 73 & 53 & 73 & 53 & 56 & 42 & 57 & 56 & 45 & 51 & 47 & 55 & 60 & 54 & 49 & 46 & 49 & 45 & 39 & 58 & 40 & 56 & 46 & 46 & 43 & \\
\hline
\end{tabular}




\begin{tabular}{|c|c|c|c|c|c|}
\hline & SUMATORIO & MEDIA & $\begin{array}{l}\text { DESVIACIÓN } \\
\text { TÍPICA }\end{array}$ & \begin{tabular}{|c|} 
ÍNDICE DE \\
DIFERENCIACION \\
\end{tabular} & LOCALIDAD \\
\hline 100 & 1728 & 49,37 & 12,75 & 0,493 & Nogueras \\
\hline 101 & 1617 & 46,2 & 13,06 & 0,462 & Ferreruela \\
\hline 102 & 1660 & 47,42 & 12,56 & 0,474 & Muniesa \\
\hline 103 & 1727 & 49,34 & 12,73 & 0,493 & Bello \\
\hline 104 & 1503 & 42,94 & 13,94 & 0,429 & Barrachina \\
\hline 200 & 1898 & 54,22 & 10,21 & 0,542 & Híjar \\
\hline 201 & 1957 & 55,91 & 9,05 & 0,559 & Alcañiz \\
\hline 202 & 2835 & 81 & 8,22 & 0,81 & Calaceite \\
\hline 203 & 1758 & 50,22 & 9,51 & 0,502 & Alloza \\
\hline 204 & 2204 & 62,97 & 3,45 & 0,629 & La Codoñera \\
\hline 205 & 2545 & 72,71 & 7,75 & 0,727 & Valderrobres \\
\hline 206 & 1671 & 47,74 & 10,75 & 0,477 & Estercuel \\
\hline 207 & 2568 & 73,37 & 7,87 & 0,733 & Peñarroya \\
\hline 300 & 1656 & 47,31 & 10,91 & 0,473 & Montalbán \\
\hline 301 & 1757 & 50,2 & 11,28 & 0,502 & Torrijo del Campo \\
\hline 302 & 1627 & 46,48 & 11,76 & 0,464 & Visiedo \\
\hline 303 & 1827 & 52,2 & 12,1 & 0,522 & Villar del Saz \\
\hline 304 & 1726 & 49,31 & 11,91 & 0,493 & Santa Eulalia \\
\hline 305 & 1565 & 44,71 & 12,28 & 0,447 & Alfambra \\
\hline 306 & 1684 & 48,11 & 11,93 & 0,481 & Noguera \\
\hline 307 & 1823 & 52,08 & 8,91 & 0,52 & Cedrillas \\
\hline 308 & 1705 & 48,71 & 12,09 & 0,487 & Teruel \\
\hline 400 & 1818 & 51,94 & 9,54 & 0,519 & Mas de Ias Matas \\
\hline 401 & 1959 & 55,97 & 7,52 & 0,559 & Bordón \\
\hline 402 & 1492 & 42,62 & 12,26 & 0,426 & Aliaga \\
\hline 403 & 1777 & 50,77 & 10 & 0,507 & Tronchón \\
\hline 404 & 1629 & 46,54 & 9,73 & 0,465 & Fortanete \\
\hline 405 & 1786 & 51,02 & 8,58 & 0,51 & Iglesuela del Cid \\
\hline 406 & 1676 & 47,88 & 11,54 & 0,478 & Alcalá \\
\hline 500 & 1956 & 55,88 & 9,42 & 0,558 & Masegoso \\
\hline 501 & 1807 & 51,62 & 9,78 & 0,516 & Puebla de Valverde \\
\hline 502 & 1764 & 50,4 & 10,18 & 0,504 & Riodeva \\
\hline 503 & 1827 & 52,2 & 8,99 & 0,522 & Manzanera \\
\hline 504 & 1838 & 52,51 & 9,54 & 0,525 & Arcos de las Salinas \\
\hline 600 & 1823 & 52,08 & 9,16 & 0,52 & Puertomingalvo \\
\hline 601 & 1879 & 53,68 & 9,01 & 0,536 & Olba \\
\hline & $\begin{array}{c}\text { TOTAL } \\
\mathbf{6 6 0 7 2} \\
\end{array}$ & $\begin{array}{l}\text { TOTAL } \\
\mathbf{1 8 8 7 , 6 3} \\
\end{array}$ & & & \\
\hline & MEDIA 1835 & MEDIA 52,43 & MEDIA 10,28 & MEDIA $\mathbf{0 , 5 2 4}$ & \\
\hline
\end{tabular}

Tabla 6. Elaboración estadística de la matriz de diferenciación 


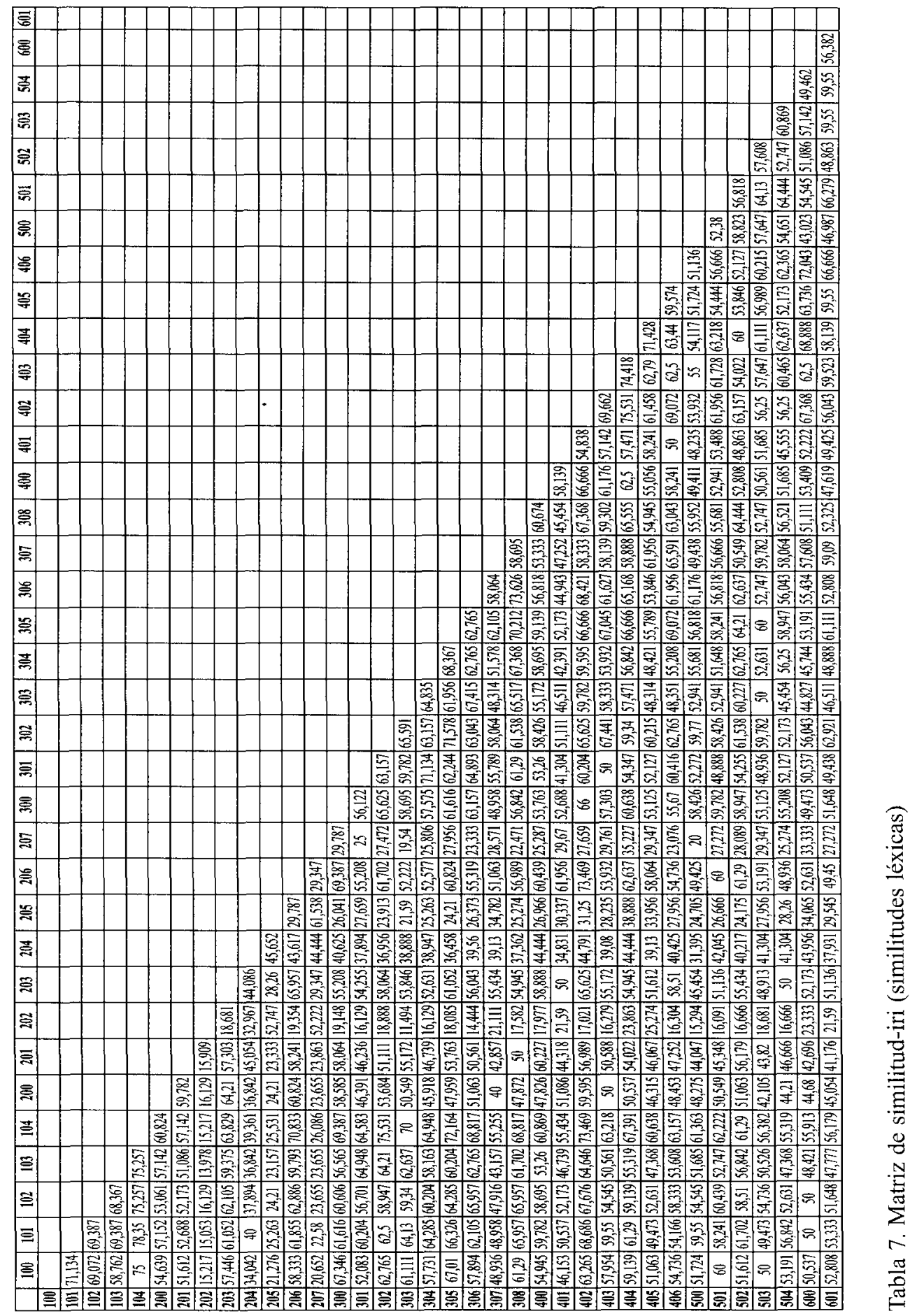




\begin{tabular}{|c|c|c|c|c|c|}
\hline & MEDIA & MÍNIMA & MÁXIMA & $\begin{array}{l}\text { ÍNDICE DE } \\
\text { SIMETRÍA }\end{array}$ & \\
\hline 100 & 53,727 & 15,217 & 75 & 1,395 & Nogueras \\
\hline 101 & 56,36 & 15,053 & 78,35 & 1,39 & Ferreruela \\
\hline 102 & 55,423 & 16,129 & 75,257 & 1,357 & Muniesa \\
\hline 103 & 53,086 & 13,978 & 75,257 & 1,417 & Bello \\
\hline 104 & 60,715 & 15,217 & 78,35 & 1,29 & Barrachina \\
\hline 200 & 48,292 & 16,129 & 60,824 & 1,259 & Hijar \\
\hline 201 & 48,059 & 15,909 & 60,227 & 1,253 & Alcañiz \\
\hline 202 & 20,092 & 11,494 & 52,747 & 2,625 & Calaceite \\
\hline 203 & 53,203 & 18,681 & 65,957 & 1,239 & Alloza \\
\hline 204 & 39,769 & 31,395 & 45,652 & 1,147 & La Codoñera \\
\hline 205 & 29,515 & 21,276 & 61,538 & 2,084 & Valderrobres \\
\hline 206 & 55,322 & 19,354 & 73,469 & 1,328 & Estercuel \\
\hline 207 & 28,616 & 19,54 & 61,538 & 2,15 & Peñarroya \\
\hline 300 & 55,05 & 19,148 & 69,387 & 1,26 & Montalbán \\
\hline 301 & 52,28 & 16,129 & 71,134 & 1,36 & Torrijo del Campo \\
\hline 302 & 57,23 & 18,888 & 75,531 & 1,319 & $\begin{array}{l}\text { Visiedo } \\
\end{array}$ \\
\hline 303 & 52,556 & 11,494 & 70 & 1,331 & Villar del Saz \\
\hline 304 & 53,28 & 16,129 & 71,134 & 1,335 & Santa Eulalia \\
\hline 305 & 58,006 & 18,085 & 72,164 & 1,244 & Alfambra \\
\hline 306 & 56,011 & 14,444 & 73,626 & 1,314 & Noguera \\
\hline 307 & 51,24 & 21,111 & 65,591 & 1,28 & Cedrillas \\
\hline 308 & 55,898 & 17,582 & 73,626 & 1,317 & Teruel \\
\hline 400 & 53,117 & 17,977 & 66,666 & 1,255 & Mas de las Matas \\
\hline 401 & 48,113 & 21,59 & 61,956 & 1,287 & Bordón \\
\hline 402 & 59,952 & 17,021 & 75,531 & 1,259 & Aliaga \\
\hline 403 & 55,444 & 16,279 & 74,418 & 1,342 & Tronchón \\
\hline 404 & 58,418 & 23,863 & 75,531 & 1,292 & Fortanete \\
\hline 405 & 52,591 & 25,274 & 71,428 & 1,358 & Iglesuela del Cid \\
\hline 406 & 55,052 & 16,304 & 72,043 & 1,308 & Alcalá \\
\hline 500 & 49,628 & 15,294 & 61,363 & 1,236 & Masegoso \\
\hline 501 & 53,568 & 16,091 & 66,279 & 1,237 & Puebla de Valverde \\
\hline 502 & 53,526 & 16,666 & 64,444 & 1,203 & Riodeva \\
\hline 503 & 51,645 & 18,681 & 64,13 & 1,241 & Manzanera \\
\hline 504 & 51,151 & 16,666 & 64,444 & 1,259 & Arcos de las Salinas \\
\hline 600 & 51,357 & 23,333 & 72,043 & 1,402 & Puertomingalvo \\
\hline 601 & 50,977 & 21,59 & 66,666 & 1,307 & Olba \\
\hline & $\begin{array}{l}\text { Media } \\
51,055 \\
\end{array}$ & $\begin{array}{l}\text { Media } \\
18,027 \\
\end{array}$ & $\begin{array}{l}\text { Media } \\
68,425 \\
\end{array}$ & $\begin{array}{c}\text { Media } \\
1,38 \\
\end{array}$ & \\
\hline
\end{tabular}

Tabla 8. Elaboración estadística de la matriz de similitud-iri 


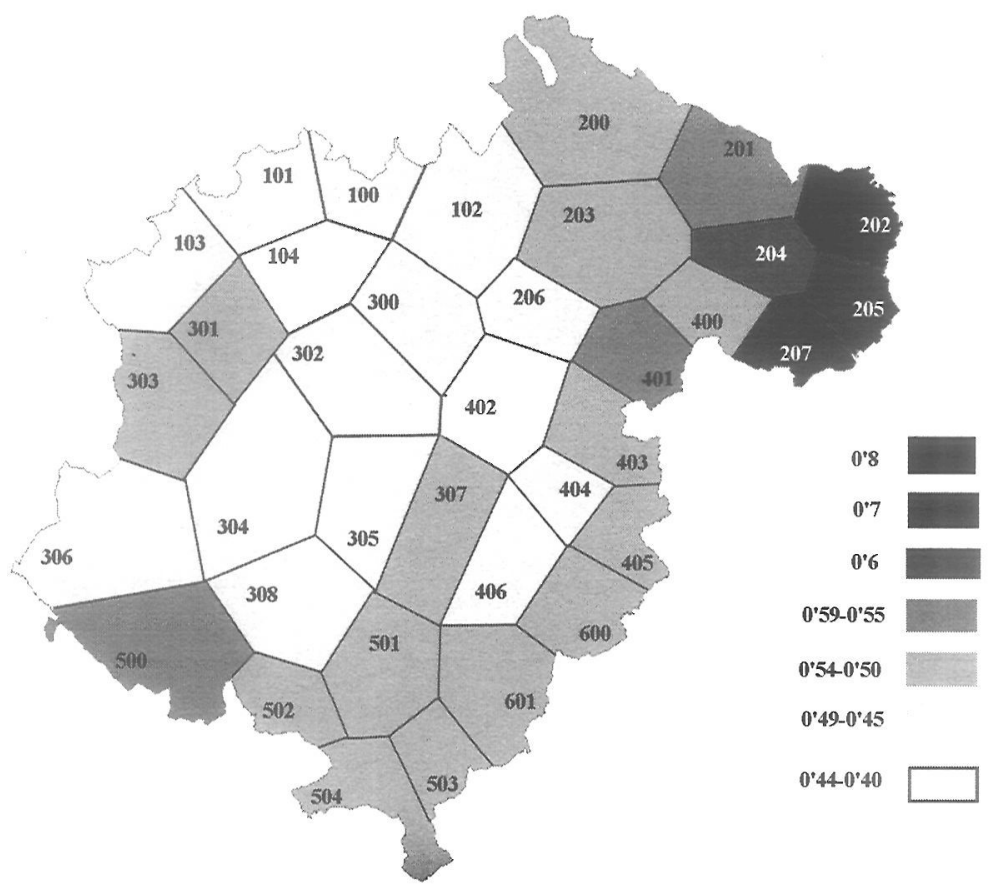

Figura 1. Mapa poligonal de la distribución del índice de diferenciación léxica

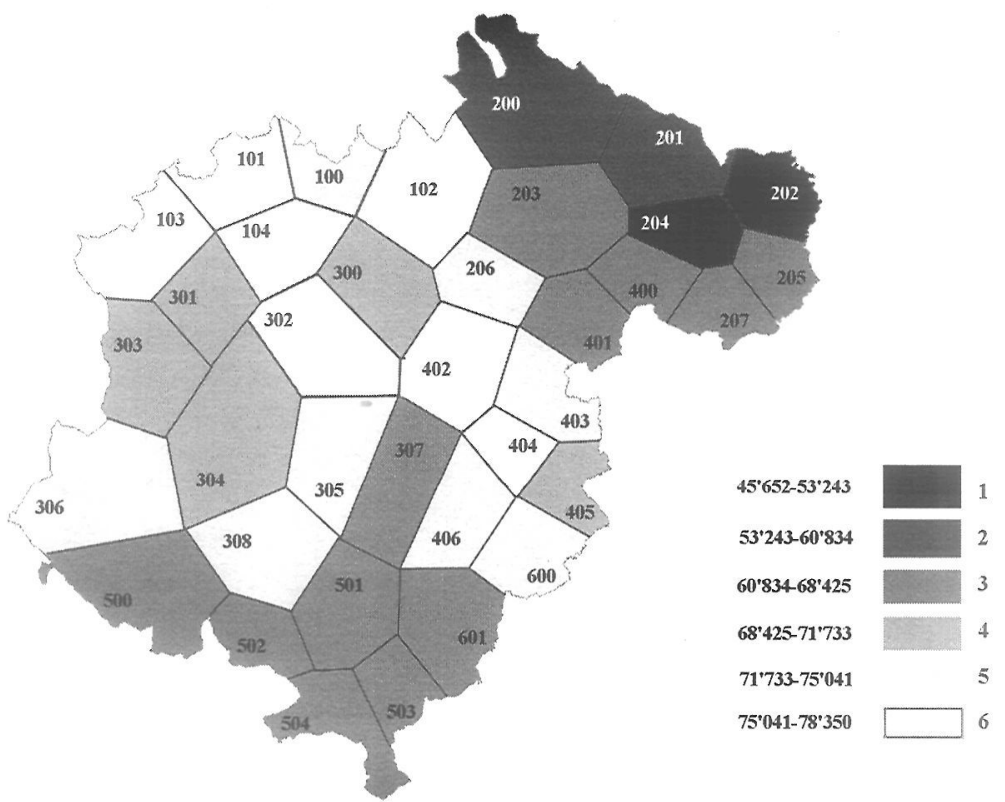

Figura 2. Mapa poligonal de la distribución de los valores máximos del IRI (MINMWMAX) 


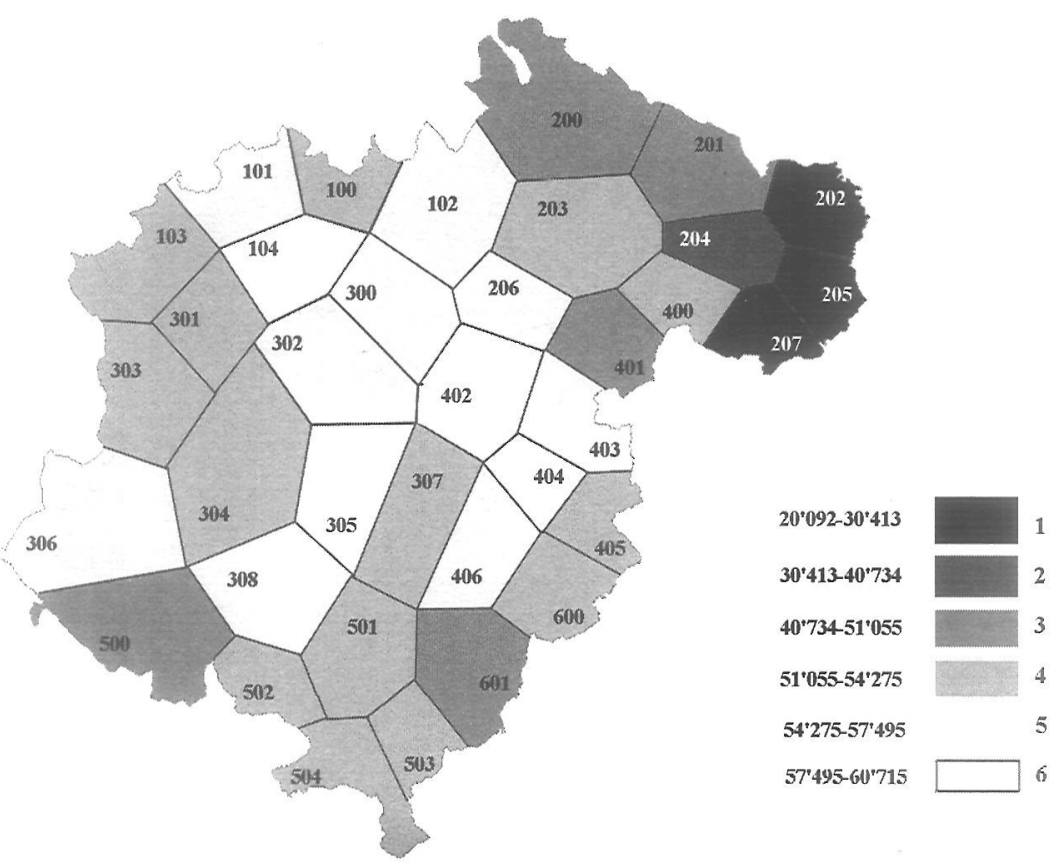

Figura 3. Mapa poligonal de la distribución de la media del IRI (MINMWMAX)

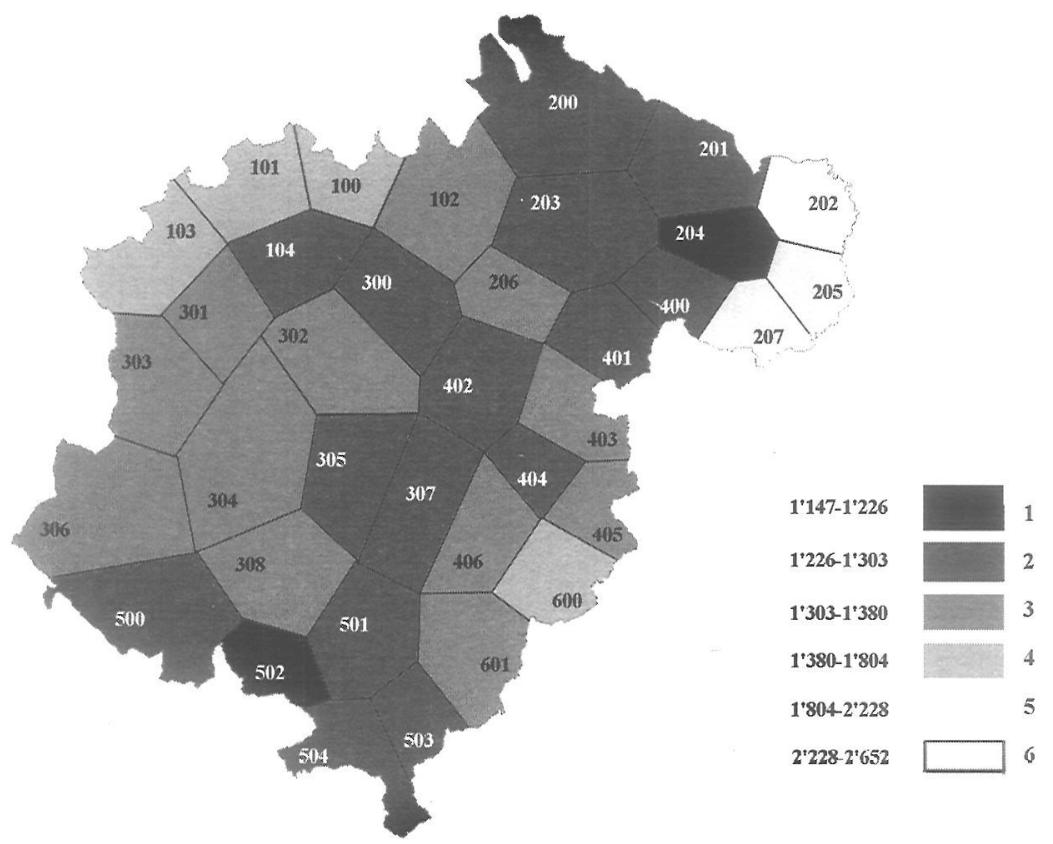

Figura 4. Mapa poligonal de la distribución del índice de simetría (MINMWMAX) 


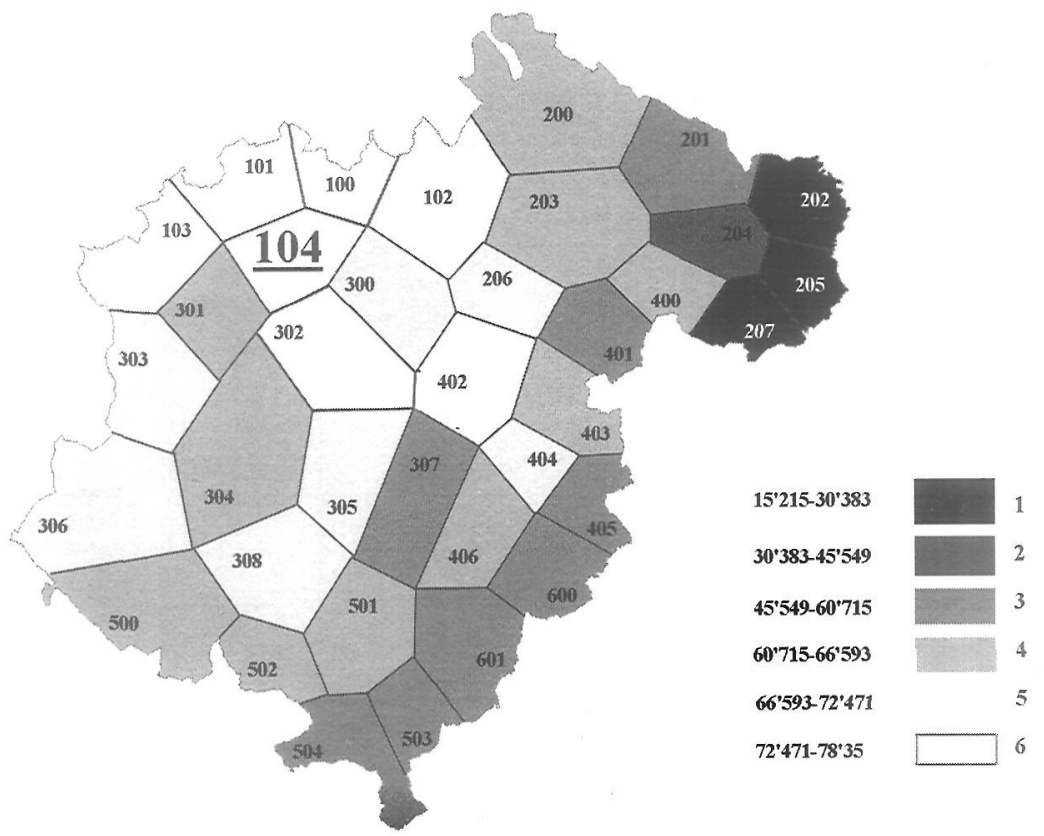

Figura 5. Mapa poligonal de la distribución de similitud relativa al punto 104 (Barrachina) (MINMWMAX)

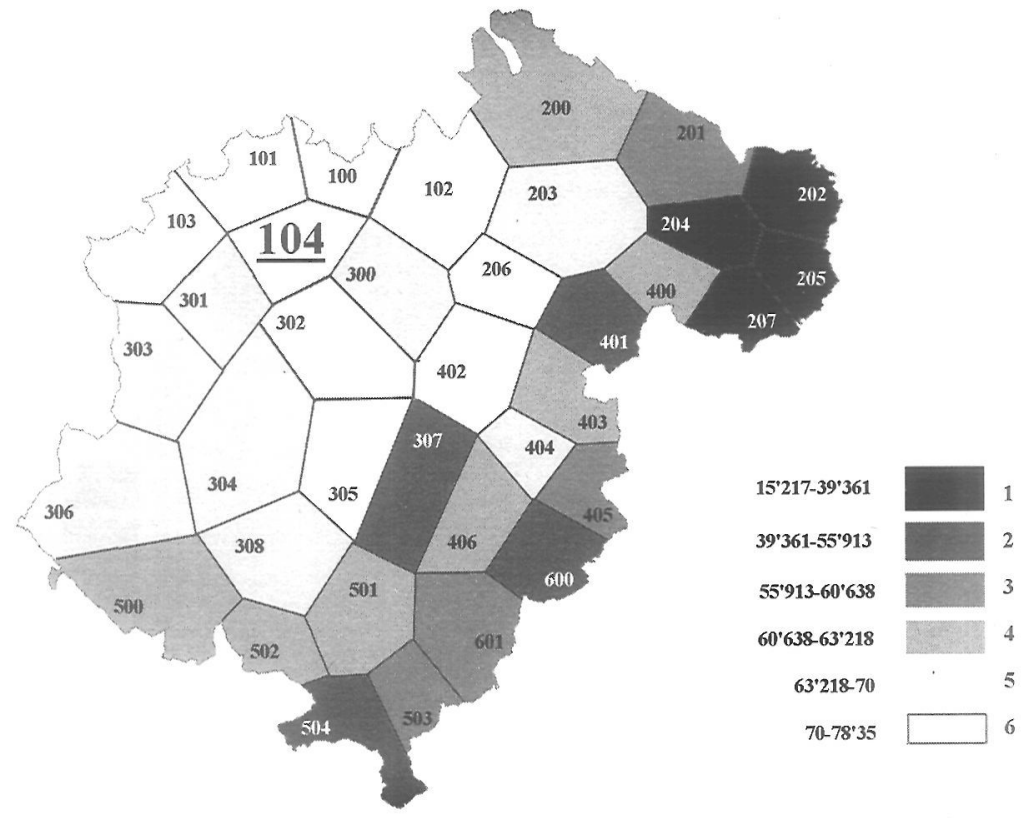

Figura 6. Mapa poligonal de la distribución de similitud relativa al punto 104 (Barrachina) (MEDMW) 


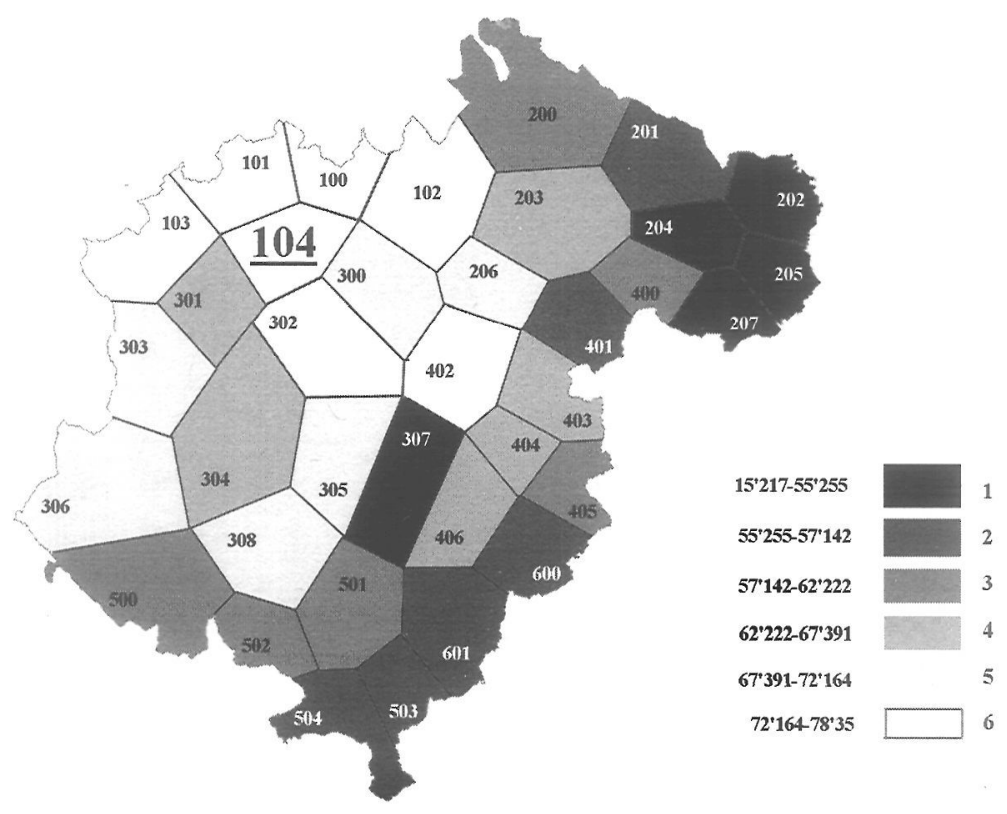

Figura 7. Mapa poligonal de la distribución de similitud relativa al punto 104 (Barrachina) (MED)

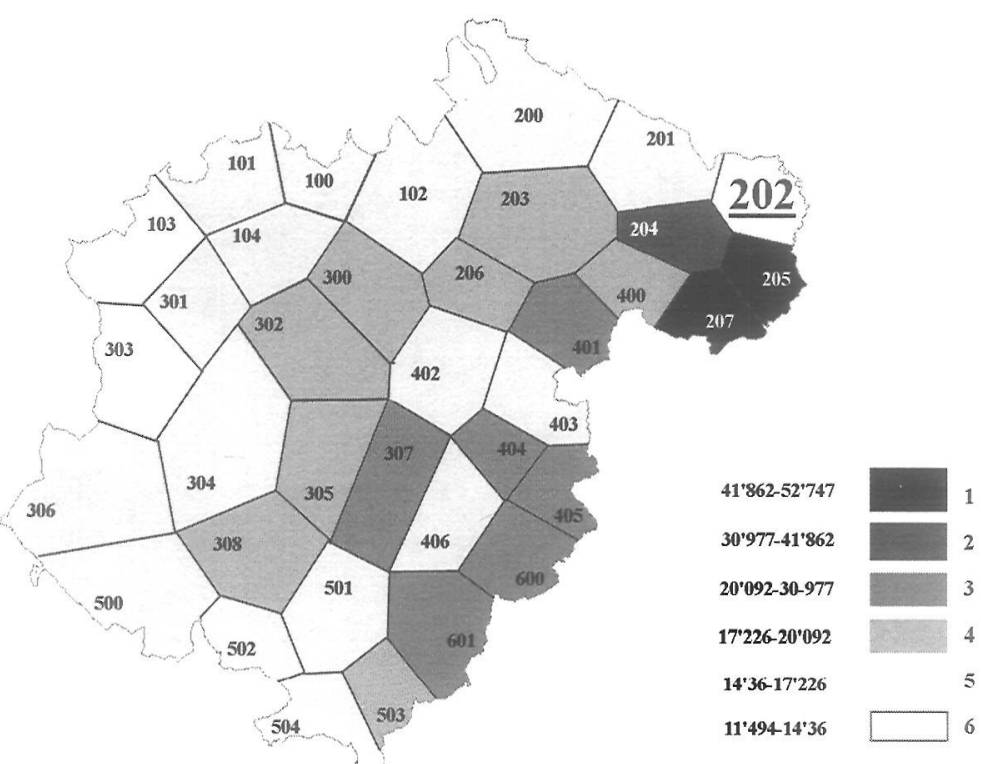

Figura 8. Mapa poligonal de la distribución de similitud relativa al punto 202 (Calaceite) (MINMWMAX) 


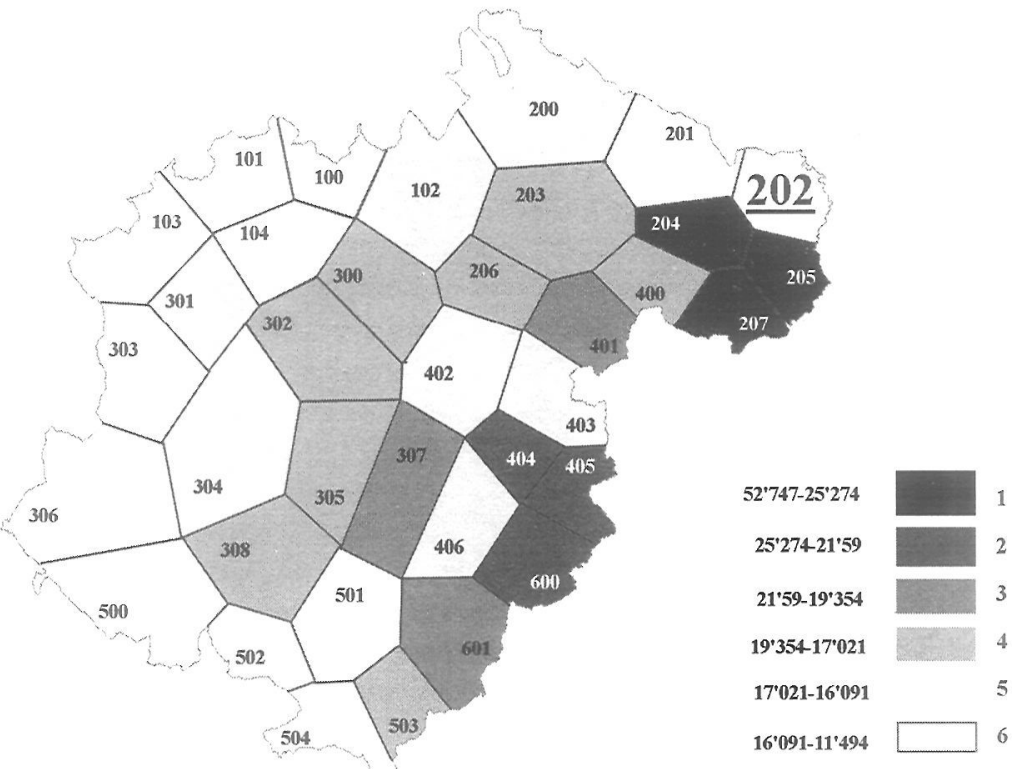

Figura 9. Mapa poligonal de la distribución de similitud relativa al punto 202 (Calaceite) (MEDMW)

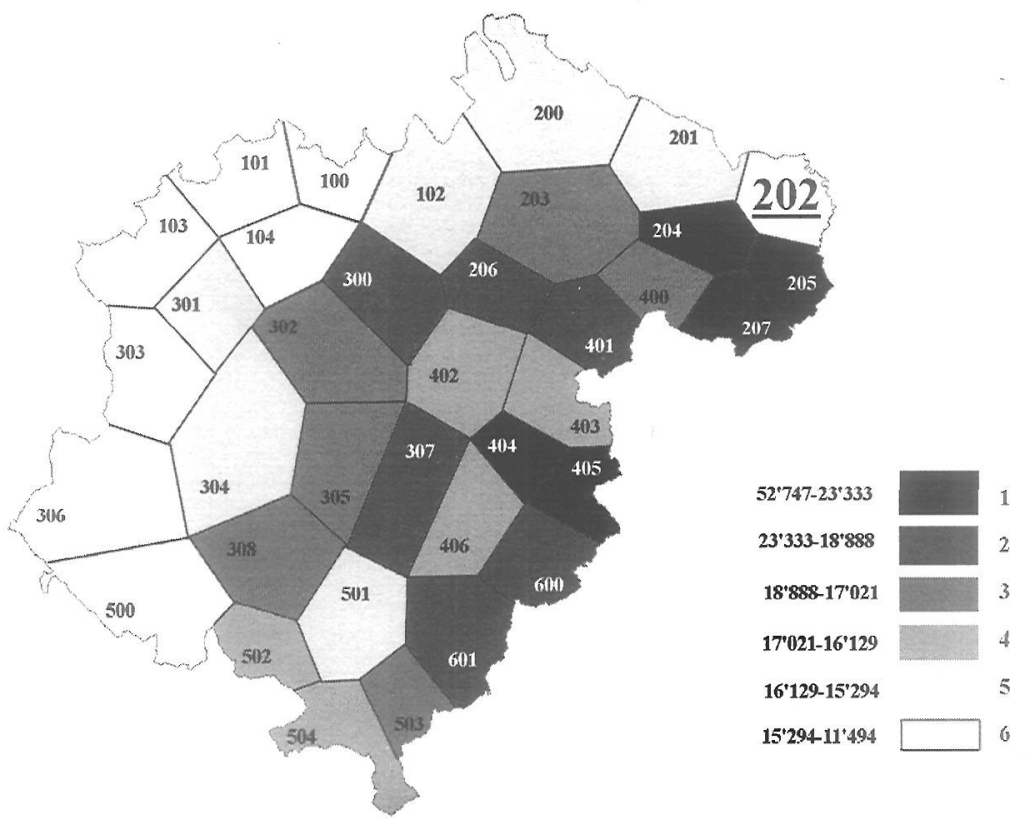

Figura 10. Mapa poligonal de la distribución de similitud relativa al punto 202 (Calaceite) (MED) 


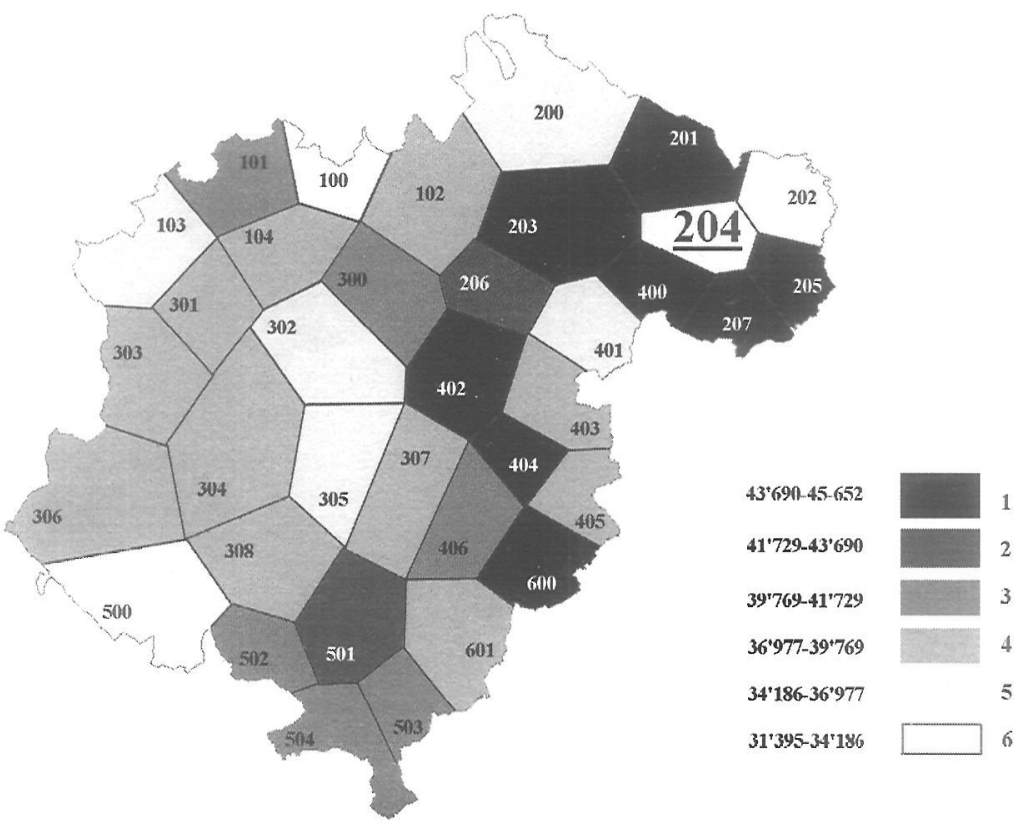

Figura 11. Mapa poligonal de la distribución de similitud relativa al punto 204 (La Codoñera) (MINMWMAX)

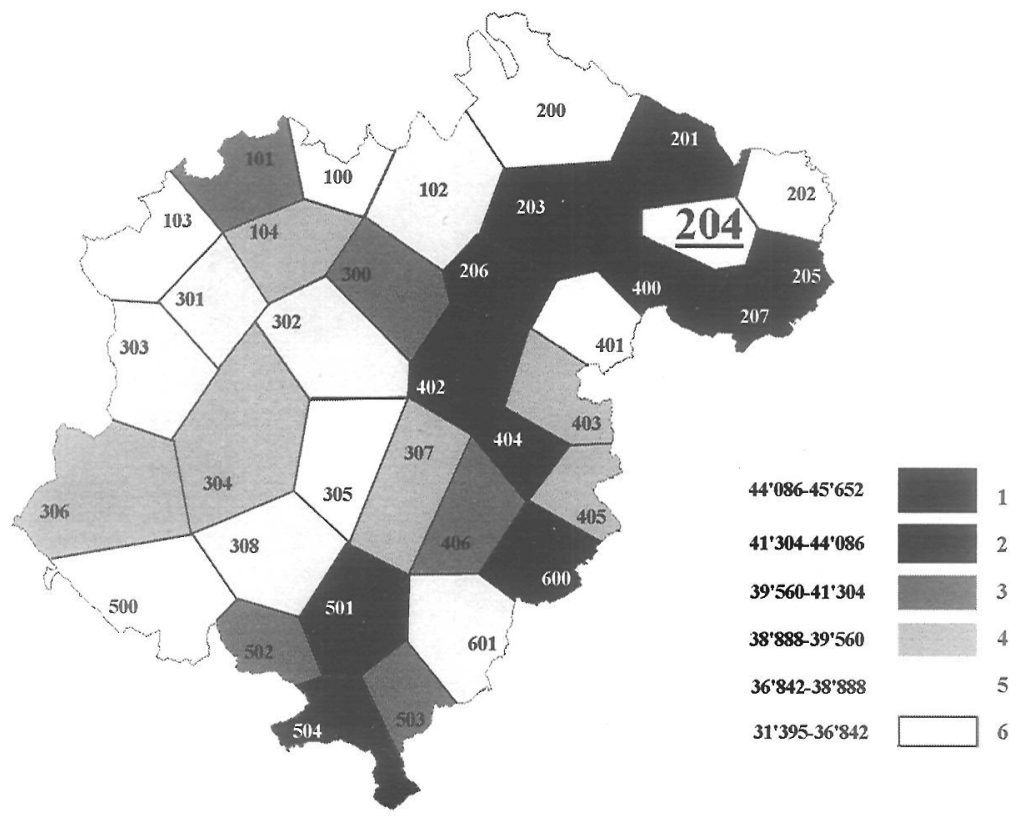

Figura 12. Mapa poligonal de la distribución de similitud relativa al punto 204 (La Codoñera) (MEDMW) 


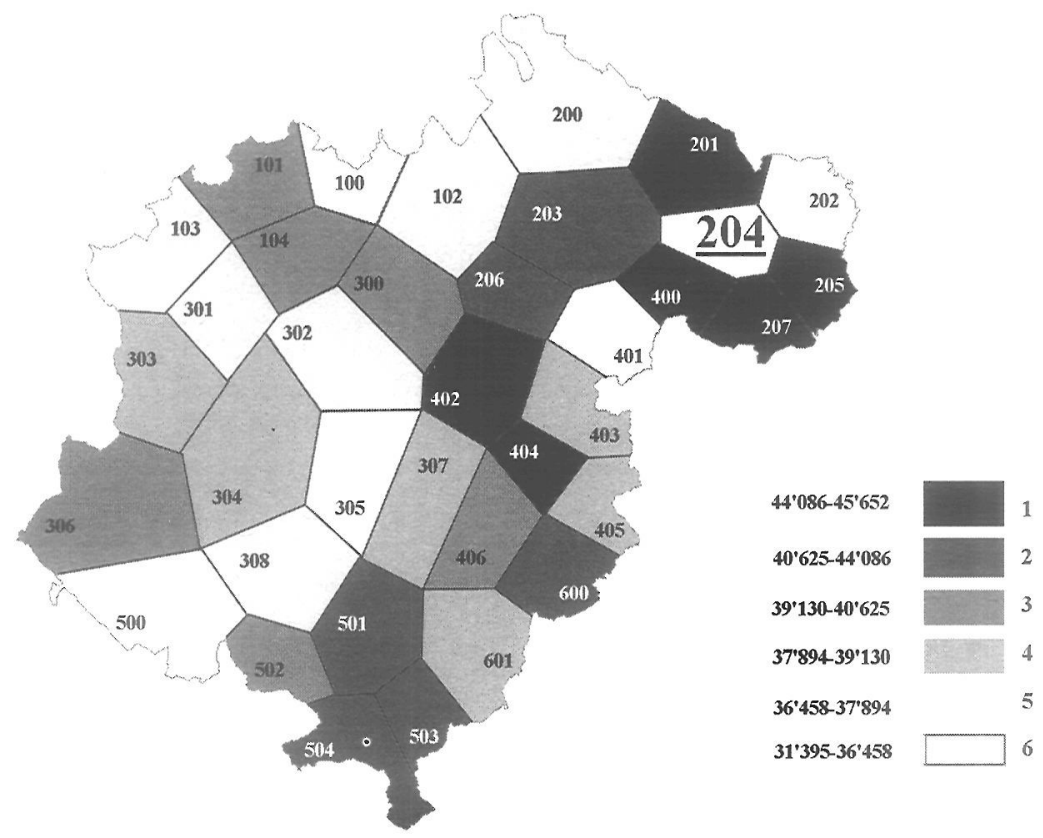

Figura 13. Mapa poligonal de la distribución de similitud relativa al punto 204 (La Codoñera) (MED) 